\title{
Kinetic Vitrification of Spermatozoa of Vertebrates: What Can We Learn from Nature?
}

\author{
I.I. Katkov** et al. ${ }^{*}$ \\ CELLTRONIX and Sanford-Burnham Institute for Medical Research, \\ San Diego, California,
} USA

Dedicated to the memory of Father Basile J. Luyet (1897-1974)

\section{Introduction}

This as well as two other related Chapters, by Isachenko et al. and Moskovtsev et al., open this Book neither accidentally nor by the Editor's preferences to his friends and collaborators; the reasons, in fact, lie quite deeper:

Why sperm? Cryobiology had actually started from freezing sperm. We will skip all those very early anecdotes but should mention the Spallanzani attempt to freeze frog semen in the 18th century [Spallanzani, 1780]. Cryobiology as a science started with revolutionizing work of Father Luyet and other scientists of the late 1930's and 1940's, who we can collectively call "the pioneers of the cryobiological frontiers" (see the following sub-Chapter). There were several reasons why sperm was chosen, which included easiness in obtaining the samples, clear evidence of viability (moving - not moving, though later it was figured that everything was not so easy in this sophisticated living "cruise missile"), and importance for the farming industry with the emergence of systematic selective breeding (especially in cattle) with a powerful tool - artificial insemination (AI). AI started with the revolutionary work of W. Heape, I.I. Ivanov and other scientists at the dawn of the 20th century and was further developed by V.K. Milovanov in the 1930's as a viable breeding technology (see [Foote,

\footnotetext{
${ }^{*}$ V.F. Bolyukh², O.A. Chernetsov ${ }^{3}$, P.I. Dudin ${ }^{4}$, A.Y. Grigoriev 5 , V. Isachenko ${ }^{6}$, E. Isachenko ${ }^{6}$, A.G.-M. Lulat', S.I. Moskovtsev",8, M.P. Petrushko9, V.I. Pinyaev ${ }^{9}$, K.M. Sokol ${ }^{10}$, Y.I. Sokol ${ }^{2}$, A.B. Sushko ${ }^{3}$ and I. Yakhnenko ${ }^{1}$

${ }^{1}$ CELLTRONIX and Sanford-Burnham Institute for Medical Research, San Diego, California, USA

${ }^{2}$ Kharkov National Technical University "KhPI", Kharkov, Ukraine

${ }^{3}$ Animal Reproduction Center, Kulinichi, Kharkov region, Ukraine

${ }^{4}$ Raptor Restoration and Reintroduction Program, National Reserve "Galichya Gora", Voronezh region, Russia

${ }^{5}$ Kharkov Zoo, Kharkov, Ukraine

${ }^{6}$ Dept. Obstetrics and Gynecology, Ulm University, Germany

${ }^{7}$ CReATe Fertility Center, Toronto, Ontario, Canada

${ }^{8}$ Dep. Obstetrics and Gynecology, Toronto University, Toronto, Ontario, Canada

${ }^{9}$ ART Clinic, Kharkov, Ukraine

${ }^{10}$ Kharkov National Medical University, Kharkov, Ukraine

** Corresponding Author
} 
2002] and [Milovanov, 1962] for detailed history of AI). Whatever case(s) for such specific interest to freezing sperm had been, it was the first subject of systematic research in cryobiology. For a long time after the 1940's, cryopreservation (CP) of sperm would be overshadowed by successes in CP of other types of cells: peripheral blood, blood, embryos, cord blood, stem cells, and other cells, tissues and organs. However, the recent progress and rejuvenation of the old method of sperm vitrification (see following Chapters by Isachenko and Moskovtsev) makes us to believe that it can bring a new shift in the cryobiological paradigm, which we will discuss later in this Chapter.

Why vitrification? As we will discuss below, the only method of stable and long-term (practically infinite) preservation and storage of any perishable biological materials, particularly cells, (a.k.a. "biostabilization") is to keep them in the glassy (vitreous) state. This was clearly understood by Father Luyet when he titled his pioneering work "The vitrification of organic colloids and of protoplasm" and "Revival of frog's spermatozoa vitrified in liquid air" [Luyet \& Hodapp, 1938; Luyet, 1937]. He and other "pioneers of the cryobiological frontiers" clearly understood 70 years ago that only glassy state would insure stable and non-lethal preservation of cells. With time, we saw the development of a variety of biopreservation methods,such as slow freezing (which, as we will see below, is just a way of achieving glassy state inside the cells and within their close vicinity - cells cannot live neither within ice without a glassy border between cells and ice, or with ice within them). Another method is equilibrium vitrification with large amounts of exogenous thickeners (vitrification agents, or VFAs). Eventually, many cryobiologists, especially the new generation and many practitioners, have forgotten that all those methods are basically different ways of achieving vitrification of the intracellular milieu (or at least, without the formation of intracellular types of ice that kill the cells) and the cell's close extracellular vicinity. This has led to several common misconceptions:

- The fact that permeable substances such as glycerol, dimethyl sulfoxide (DMSO), ethylene glycol (EG), propylene glycol (PG or PrOH) and some other small permeable compounds play absolutely different roles during slow freezing, when they serve mainly as osmotic buffers and during vitrification (VF), when they play the role of thickeners so they increase viscosity and deplete growth and propagation of ice. As a result, in both cases, these substances are called "cryoprotective agents" (CPA's) across the board even though the concentrations used, the modes of addition and elution, and the mechanisms of action are very different for the cases of slow freezing (SF) vs. equilibrium vitrification $(\mathrm{E}-\mathrm{VF})$ and kinetic vitrification $(\mathrm{K}-\mathrm{VF})$ (we will explain the difference between $\mathrm{E}-\mathrm{VF}$ and K-VF later). We prefer to distinguish these two roles and call $10 \%$ of DMSO used for slow freezing of stem cells as "CPA" and $40 \%$ of DMSO used for equilibrium VF of embryos of kidneys as "VFA". As we can see however, for kinetic VF, even $10 \%$ of glycerol can help vitrify the cells and can be used as the vitrification agent (with some reservation).

- The second misconception that has an even larger implication and can be seen mainly in the work of practitioners is that slow freezing is often called "cryopreservation" and is contrasted to vitrification. It is all essentially cryopreservation, just by different methods. Moreover, it is actually vice versa: slow freezing ("cryopreservation" in their terms) is just a way of intracellular vitrification with ice being present in the extracellular compartment (see below for details). We can see such erroneous terminology in some Chapters of this Book (especially in Volume 2). The Editor, however, has decided to keep a democratic approach and not impose his point of view, thereby letting the reader understand their mistakes after reading this Chapter for future publications. It is the authors' choice to use 
incorrect terminology, and as the result, to be a target of criticism in following publications.

- The drastic decrease in the rate of degradation at low temperatures is contributed not only (and not mainly) by the simple Arrhenius decreases of the rate of a chemical reaction at lower temperature as all molecules per se move slower at lower temperatures even in a vacuum or air as suggested in [Suzuki, 2006]. The practically infinite stability in the vitreous state is achieved mainly due to the enormous increase in viscosity of the surrounding milieu, which at the glass transition point is determined as $10^{13.6} \mathrm{~Pa} \times \mathrm{sec}$. At such conditions, according to the Einstein-Stokes Law, the destructive molecules such as reactive oxygen species can reach a biomolecule in time that is longer than the age of the universe [Katkov \& Levine, 2004]. This is true in the opposite way as well; the degradation of the sperm after freeze-drying at different temperatures, as observed by Suzuki, had occurred mainly because the cells were kept at some level above the crucial temperature of the glass transition $\left(T_{g}\right)$ : As higher the cells are kept above $T_{g}$, as more soft (rubbery) and later liquid the sample became, therefore the cells degraded more rapidly. We can judge from Fig. 1 in Suzuki's paper that intracellular $T_{g}$ was above $80^{\circ} \mathrm{C}$ but below $+4{ }^{\circ} \mathrm{C}$, a typical scenario for lyophilization of sperm and other cells.

Why kinetic? As we will also discuss below, the modern shift from Fahy's equilibrium back to Luyet's kinetic vitrification has brought not only clear technical advantages and better survival of oocytes and embryos. The resurrection and successful re-emergence by the Isachenkos of the Luyet's method in regards to the very subject he and other "pioneers of the cryobiological frontiers" attempted to preserve more than 70 years ago - the sperm, has not only brought a simple and convenient technique to the field of assisted reproduction (human spermatozoa first, then animal ones followed). As we can see later in this Chapter, both success of K-VF for some species of sperm and failure of the same method for the others would prompt us to a more general idea: the "Universal Cryopreservation Protocol", which could have a much broader impact and if realized physically by a new type of cryogenic devices that would insure hyperfast cooling and warming, it would shift the whole cryopreservation paradigm. We feel that we will soon witness some sort of a "Kinetic Vitrification Spring" as to draw a political analogy, and that is why we have put these three Chapters at the spearhead of the Book.

In this Chapter, we summarize the basic thermodynamical and biophysical distinctions between $\mathrm{K}-\mathrm{VF}, \mathrm{E}-\mathrm{VF}$, slow freezing (SF), analyze present and predict future developments that will widen the K-VF niche, and hypothesize why K-VF of some species of sperm was more successful than the others. We then briefly explore our idea that with the development of a new generation of hyper-fast cooling devices (up to several hundred of thousand oC/min), we will witness the "Race for the Pace" for the Universal Cryopreservation Protocol without any exogenous VFA's that can be applicable to any cell type.

\section{Brief history of kinetic vitrification of sperm and cryobiology in general related to the goal of this Chapter}

\subsection{Early attempts of kinetic vitrification of sperm and other cells}

In the dawn of cryopreservation, vitrification of small samples by ultra-fast cooling (tens of thousands $\mathrm{OC} / \mathrm{min}$ ) without additional thickening and ice-blocking agents (VFAs), which is 
referred here as kinetic VF, had been considered as the major method of cryopreservation at that time [Graevsky, 1948a, b; Graevsky \& Medvedeva, 1948; Hoagland \& Pincus, 1942; Jahnel, 1938; Luyet \& Hodapp, 1938; Luyet, 1937; Park et al., 2004; Schaffner, 1942]. Note that some authors contributed the first understanding of the importance of vitrification for biopreservation to a an earlier work of Walter Stiles [Stiles, 1930], as it, for example, is done in [Fahy \& Rall, 2007]; we think, the Stiles's notion however was vague and had had a marginal impact. It was Luyet's work, which would make cryopreservation a science. From the outset, he recognized that ice damage must be avoided and vitrification could be a method for long-term preservation of cell viability [Luyet, 1937]. In 1938 Luyet and Hodapp achieved survival of frog spermatozoa vitrified by plunging into liquid air [Luyet \& Hodapp, 1938], and later several Western European groups reported their experiences with attempts in kinetic vitrification of fowl [Schaffner, 1942], human [Hoagland \& Pincus, 1942; Jahnel, 1938; Parkes, 1945], and rabbit spermatozoa [Hoagland \& Pincus, 1942] with varying success. While not directly related to the K-VF of sperm, a clear notion of vitrification as the only way of viable stabilization of cells has been expressed by Graevsky in USSR. As he worked with bacteria, it was natural to use a bacterial sample collection loop to freeze the cells in thin pellicles [Graevsky, 1948a, b]. A similar approach was used by Hoagland and Pincus in Germany in 1942 [Hoagland \& Pincus, 1942], which seems a very natural approach for very fast K-VF. Yet, in the money-driven 21st century, the term "Cryoloop" is a registered as a trademark. Apparently, those early scientists would have infringed the trademark law now!

These early efforts of K-VF of sperm did not receive the recognition they deserved, hindered by the low repeatability and poor survival, as well as difficulties in communication due to various "iron walls" that existed between scientists of the Western Allies, Germany and USSR in the era of WWII followed by the Cold War.

\subsection{The rise of slow freezing}

The breakthrough came from an independent discovery of the protective role of a permeable CPA glycerol by two groups in 1948-49 [Polge et al., 1949; Smirnov, 1949].The high permeability of glycerol to the sperm membrane in conjunction to relatively low toxicity seemed to be the crucial factor; both groups unsuccessfully tried either non-permeable sugars such as glucose (Parkes's group) or very permeable but very toxic lower alcohols such as ethanol or methanol (Smirnov). The high membrane permeability of glycerol and, thus, fast penetration inside the cells allowed to preserve the cells using slow (10-40 $\mathrm{O} C / \mathrm{min}$ ) freezing, and very moderate warming rates by direct thawing on air or in a water bath. It then became the mainstream of the cryopreservation methods, and a vast variety of cell species of different biological taxa have been preserved by slow (also called equilibrium) freezing. It revolutionized two very important fields: the cattle industry (with preservation of bovine sperm and later bovine embryos) and cryopreservation of blood components. It is worth noting that 12 years before the discovery of Parkes's and Smirnov's groups, Bernstein and Petropavlovski had reported the protective role of glycerol during the freezing of sperm [Bernstein \& Petropavlovski, 1937] to $-20^{\circ}$ C, but that work had gone largely unnoticed.

With the development of Peter Mazur's equations and the 2-factor hypothesis of cryodamage [Mazur, 1963; Mazur et al., 1972] and work of other cryobiologists on slow (equilibrium) freezing in 1960's, it became clear that a particular cell would need its own optimal cryopreservation protocol, which would largely depend on the cell cryobiological and physiological parameters as well as on the type of cryoprotective agents (CPA's) used. 
Particularly, equilibrium CP of embryos would require much slower pace of cooling (0.3-1 $\mathrm{OC} / \mathrm{min}$ ) so the whole cryopreservation process would take several hours.

Following cryopreservation of animal spermatozoa, the successful slow freezing of human sperm with glycerol followed, and the first birth was reported by Sherman and colleagues 1964 [Perloff et al., 1964]. It was then followed by the use of frozen spermatozoa for practically all assisted reproduction techniques (ART) mentioned above. Yet, since his first publications, Sherman had questioned the efficiency of glycerol as the ideal CPA for human spermatozoa [Sherman, 1963, 1964]. The addition and especially removal of permeable osmotically active cryoprotective agents (cryoprotectants) during freezing and warming can induce a lethal mechanical stress per se. Further problems include the chemical toxicity of cryoprotectants and the possible negative influence on the genetic apparatus of the mammalian spermatozoa [Gilmore et al., 1997].

\subsection{The emerging of equilibrium vitrification}

On the other hand, Greg Fahy and colleagues [Fahy et al., 1984] reported the vitrification of a whole organ--a rabbit kidney--using high pressure and extremely high concentrations of permeable vitrificants. We will call that approach, which for all intents and purposes will be clarified later, equilibrium vitrification. The needs of more quick and robust methods of cryopreservation of mammalian embryos had been clear, since Mazur and colleagues and Wilmut had obtained the "frozen mice" by SF in 1972 [Whittingham et al., 1972; Wilmut, 1972].Plus, Fahy's initial report led to the collaboration between him and W. Rall (former Mazur's student, who specialized in freezing embryos) and the first successful vitrification of mouse embryos was reported a year after Fahy's first report [Rall \& Fahy, 1985]. The first human baby from a vitrified embryo was reported in 1990 ?? [Gordts et al., 1990]. Since then, vitrification has become an equally spread assisted reproduction technique (ART) as programmed slow freezing of embryos and, especially, oocytes for in vitro fertility (IVF) (see [Rezazadeh et al., 2009] for examples and background).

For detailed state of the art of vitrification of reproduction cells, see several Chapters of this Book and Book 2, as well an excellent book by Tucker and Lieberman [Tucker \& Liebermann, 2007]. Several Chapters in that book will be referred throughout this Chapter as well. Particularly, an interesting history and even possible natural occurrence of E-VF in nature is described in the Chapter 1A of that book by Fahy and Rall ("Certain Alaskan beetles dehydrate sufficiently to generate concentrations of up to $10 \mathrm{~mol} / \mathrm{L}$ of endogenous glycerol,26 which is enough to vitrify aqueous solutions under laboratory conditions") [Fahy \& Rall, 2007]. Note, however that this particular Chapter $1 \mathrm{~A}$ is substantially biased against K-VF in favor of E$\mathrm{VF}$, which we will address throughout the following sub-chapters, and toward the founder of the method, Father Luyet, including some far from diplomatic language escapades. That part will be addressed at the end of the Chapter.

\subsection{Vitrification of the majority of reproductive cells is moving from equilibrium to kinetic approach}

While slow freezing showed its limitations for certain cell types (e.g. oocytes), a new era started when Rall and Fahy vitrified mouse embryos [Rall \& Fahy, 1985] using essentially the same high concentrations of vitrificants vitrified by Fahy et al. used in its original report [Fahy et al., 1984]. However, such high concentrations $(40-60 \% \mathrm{v} / \mathrm{v})$ of VFA's such as 
glycerol, DMSO, and PG are osmotically damaging and chemically toxic so they are intolerable for many cells such as oocytes and spermatozoa, many of which can withstand at best $10-15 \%$ DMSO or glycerol. As a result, researchers moved from equilibrium VF to much more rapid kinetic vitrification that requires much lower concentrations. It is especially clear for CP of oocyte, which cannot tolerate either slow freezing or equilibrium VF apparently due to their cytoskeletal osmotic fragility. To date, many methods and sample carriers have been designed for K-VF of oocytes and embryos, but they all require small sample volumes and precise timing, which makes them vulnerable to technical errors. We will further explore this aspect in a sub-Chapter below.

\subsection{Resurrection and rise of kinetic vitrification of sperm: the Isachenkos' contribution}

The true "second wind" of the kinetic VF was brought in with re-discovering of VF of human spermatozoa without any exogenous vitrificants (a.k.a., "cryoprotectants" even though they play a completely different role than in slow equilibrium freezing) by the Isachenkos and their colleagues. It came with two seminal appears and two presentations in 2002 and 2003, which, as one of the author remembers, stirred a pot and met a lot of resistance and denial from vitrification experts and other prominent "classical" cryobiologists. In 2002, Vladimir and Evegenia Isachenkos and their colleagues reported that human sperm can be vitrified without endogenous vitrificants ("cryoprotectants" as they called it). It worked with the same success or even better than slow freezing [Nawroth et al., 2002], so the Isachenkos showed that it did work. Later, Igor Katkov joined the team and tried to explain why it actually worked in [Isachenko et al., 2003] and gave a presentation in CRYO-2003 in Coimbra [Katkov et al., 2003]). It was clearly emphasized that at least three factors might have played a crucial role in the successful K-VF of human sperm without exogenous permeating vitrificants: i) small size of the cells, ii) compartmentalization, and iii) high amount and concentration of endogenous natural vitrificants such polymers, sugars and nucleotides. We will explore those aspects later in some detail. This quite novel at the time notion is so "well known" now that does not even need mentioning the source (e.g., p.649 [Isachenko et al., 2011]); however, it was not so "obvious" back in 2003. Here we want to emphasize that despite of skepticism, denial, or even open hostility towards publications and presentations faced by the Isachenkos (and by Katkov as their strong proponent), the method had matured into a technology, which proved to be robust and feasible for ART practitioners as well brought food for thoughts to those who works in the realm of basic cryobiology. Most importantly, the results led to the birth of healthy babies and at least one group has repeated the Isachenko method and has obtained good results completely independently- they report their data in Chapter 3 [Moskovtsev et al., 2012]. The authors dedicate a separate Chapter 2 in this Book for summarizing their achievements [Isachenko et al., 2012]. Below, we not only briefly explore progress of the method but also show that even as the staunchest opponent of the method (more precisely, interpretation of the results) as Dr. Fahy has also evolved in his perception of "legitimacy" of kinetic vitrification, which we had never doubted at the beginning.

The Isachenko group has recently expanded K-VF method to other mammalian species (dogs) and to an even more distance vertebrate taxon, the fish (see below and also a separate Chapter [Isachenko et al., 2012]). However, our experiments on K-VF of sperm of rodents was not so successful, and attempts of kinetic VF of sperm of the polar bear and raptor birds (falcons and 
eagles) failed completely, which actually would prompt us to an even more interesting hypothesis of "The Universal Preservation Protocol" and prediction of the "Race for the Pace".

\section{Five basic methods of long-term cell biostabilization: pro's \& con's}

\subsection{All five basic methods of long-term biostabilization cell requires vitrification of the intracellular milieu}

We have defined 5 major ways of cell stabilization that all lead to low- or high-temperature VF of intracellular milieu as we outlined in [Katkov et al., 2006], which are shown on a schematic phase diagram (Fig. 1) adapted from [Devireddy \& Thirumala, 2011] with some corrections and additions.

Equilibrium (slow) freezing (points $A-B^{\prime}$ in green) allows to freeze-out the bulk of both extracellular and intracellular water (which escapes from the cell as the extracellular liquid phase becomes more and more concentrated) to ice. Finally, the cells are vitrified in the inter-ice "channels" that are surrounded by ice but always make a connected network (due to barometric restrictions) and surrounded by ice. Yet, the glass transition temperature in those channels is still low so the cells must be stored in $\mathrm{LN}_{2}$ at $-196{ }^{\circ} \mathrm{C}$, in nitrogen vapor, or in industrials freezers at $-130{ }^{\circ} \mathrm{C}$ and for a limited time at higher temperature than the $\boldsymbol{T}_{g}$ of water (around $-136^{\circ} \mathrm{C}$ ), for example in more accessible $-80^{\circ} \mathrm{C}$ freezers. This is the mainstream conventional cryopreservation, which in the majority of cases requires the use of permeable and impermeable cryoprotective agents (CPAs).

Ice-free equilibrium vitrification (E-VF) of cell suspensions, tissues, and organs at very low temperatures and moderate to high rates of freezing (points E-F in red). This method requires the use of high concentrations of vitrificants, which elevates the viscosity of the milieu and prevents the ice formation during cooling and de-vitrification (sometimes called re-crystallization, which is not exactly the same) during warming. Some researchers [Fahy \& Rall, 2007] refer to this method as "vitrification proper", and in its "pure form" (see below) has had very limited success in preserving animal oocytes, embryos, some tissues and one organ, as well as some plant specimens.

Intracellular ice-free kinetic vitrification of a bulk solution by very fast (abrupt) plunging into a cooling agent such as liquid nitrogen (points G-H in purple). The extremely high rate of cooling $\left(10^{4}-10^{6} \mathrm{O} / \mathrm{min}\right)$ and practically instant warming prevents ice formation inside the cells (the ice still can be formed outside but it has no time to cause any osmotic damage to the cells as K-VF occurs in fractions of a second). As the result, it does not require the use of potentially toxic high concentrations of "CPAs" (vitrificants) or no permeable exogenous vitrificants at all, it is referred to as "CPA-free vitrification" by the Isachenkos in regards to sperm. We deliberately include in this method cooling of sperm at much lower rates because the very high $T_{g}$ of the intracellular milieu does not require such high rates. This is one of the major themes of this chapter.

Slow freezing to moderately low (around -40 OC -- -600C) temperatures, which comprises two steps; i) primary drying - sublimation of the bulk of ice at very high vacuum (points A$\mathrm{D}$, and ii) secondary drying of the 'cake' at elevated (up to $+30-40 \mathrm{OC}$ ) temperatures (points D-C). This method is called lyophilization and it is widely used in food production, microbiology and in the pharmaceutical industry; but so far it has had very limited applications in the preservation of animal cells and higher plants. 
High temperature vitrification of a highly dehydrated sample (desiccation) and its stabilization by air/vacuum drying at temperatures above $\mathrm{OC}$ is so no ice is formed (points A-C in orange). In some sources, it also erroneously called "lyopreservation" [Chakraborty et al., 2011], which is incorrect as "lyo" implies sublimation (Greek luien- loosing of ice during sublimation (http://dictionary.reference.com/browse/lyo-). In contrast, the Greek word xero means "dry" (http://dictionary.reference.com/browse/xero-), thus "xerophile organisms", or even the Xerox machine! Subsequently, xeroportective agents such as trehalose are often used to prevent damage associated with high levels of dehydration when it is used in secondary drying during freeze-drying, and during the whole desiccation cycle. Note that the temperature of drying $\boldsymbol{T}_{\boldsymbol{d} r}$ is always above the glass transition temperature of the sample $T_{g}$ (blue curve) for both methods on definition (otherwise, neither sublimation nor evaporation will occur due to extremely high viscosity). For stable storage on another hand, the temperature of storage $T_{s t}$ must be below $T_{g}$, so the conditions of stable drying are following $T_{s t}<T g<T_{d r(f)}$ (final temeperature of drying). Many papers on drying of biologicals report $T_{g}$ above $T_{d r}$, which is incorrect (see [Katkov \& Levine, 2004] for details and possible explanation of such "paradox"). It can explain instability of samples at long storage [Suzuki, 2006] that are often claimed to have $T_{g}+60-70$ OC while in fact they barely exceed $0{ }^{\circ} \mathrm{C}$ or fall within the negative range and cannot be long-term stored at ambient temperatures.

The first three methods imply the low temperature and thus, are in the scope of these two books ("cryo" means cold). Biostabilization above 00C is often considered as a part of the preservation science and traditionally reported on the cryo-meeting and published in the specialized journals such as "Cryobiology", "CryoLetters" and "Problems of Cryobiology and Cryomedicine "(a bilingual journal of the Institute for Cryobiology in Kharkov, Ukraine). We deliberately excluded those topics from the scope of our Books as they need special consideration; nonetheless, we will briefly discuss some aspects below.

\subsection{At present, desiccation and especially lyophilization can not be considered as major approaches for biostabilization of viable cells}

Despite the reports of "successful" xeropreservation and lyophilization of live vertebrate cells from time to time by many groups including prominent cryobiologists since the end of 1940 's, with three notable reports of Meryman and the birth of a cow called "Desicca" (see [Suzuki, 2006] for an excellent mini-review on the topic), it turned out that neither of the methods to date have proven to produce stable and viable cells that could be stored for long periods of time. It mainly contributes to the fact that even for such good vitrificants, such as proteins, achieving a true high $T_{g}$ coincides with very low water content (in a range of $0.3 \mathrm{~g}$ $\mathrm{H}_{2} \mathrm{O}$ per $1 \mathrm{~g}$ dry weight), which apparently is not sustainable by vertebrate cells insofar. Whether the very recent reports by Devireddy and Thirumala [Devireddy \& Thirumala, 2011] and by the Mehmet Toner's group [Chakraborty et al., 2011]will change the situation, or they will fade away as all the proposed methods have so far needs to be seen. Our approach is expressed in [Katkov \& Levine, 2004; Katkov et al., 2006; Katkov, 2008]. The discussion of what has been done wrong so far, and what could and should be done, would need a separate Chapter, and as we said before, is out of the scope of this Book. However, there are two things that should be mentioned. 


\subsubsection{Freeze-drying/desiccation of spermatozoa has not produced motile and viable cells but it fits for intracellular sperm injection (ICSI) as it stabilizes the nucleus}

First, we have to remember that "successful (i.e., bringing offspring) freeze-drying or drying of spermatozoa" is a confusing and actually misleading statement. The properly freezedried/desiccated spermatozoa are dead, they are never motile, and neither do they have intact acrosome (in the majority of cases). It is the genetic apparatuses, which include such excellent endogenous vitrificants as proteins (e.g., histones), and at lesser extent, DNA that indeed can be stabilized at high temperatures (above $0{ }^{\circ} \mathrm{C}$ ) for long time by xeropreservation (preferably) or by lyophilization (if secondary drying is done properly). Naturally, if intracellular sperm injection (ICSI) is performed, both methods can and do bring offspring (see [Suzuki, 2006] for references).

\subsubsection{On reasoning of creating "xerobanks" of dried genetic material}

Secondly, as the nucleus of somatic cells can be kept intact after desiccation, it (theoretically) can be used for cloning by somatic-cell intracellular nuclear transfer (SCNT). So, those two aspects, ICSI and SCNT raise the question whether the xerobanks of both gametes and somatic cells should be created for human, model (laboratory), agricultural and wildlife species. We personally believe (though it might change with the time) that except for xerobanks of sperm of laboratory animals, such as transgenic mice and rats, for which both ICSI and SCNT have been well established [Katkov, 2008], the other types of xerobanks are not a necessity, and people should focus their resources and money (which are often scarce in this field) on the methods that have been proven to produce viable cells (i.e. on cryopreservation). In situations where the cold chain is not as easily available (for example, for the preservation of a genome of species that are on the verge of extinction), drying could be considered as the last resort, but for now, it should not be considered as an alternative to cryobanks. That might change where ICSI and SCNT become routine for many species, but so far we should concentrate on CP. And again, it is gametes, embryos and other reproductive cells that should be preserved first to save genetic material of endangered species even after their death [Maksudov et al., 2009] while, for example, the CP of stem and other somatic cells should be kept as the last resort when the reproductive cells are unavailable. Note, that some other authors of this Book are much more optimistic on that matter of both drying (e.g., the Chapter by Joseph Saragusty ([Saragusty, 2012] sub-chapters 2.3 and 4.2), and cryobanks of stem cells for restoration of species ( [Saragusty, 2012], subchapter 4.3).

\subsection{Slow freezing: Still the mainstream of cryopreservation but...}

As we mentioned above, the discovery of "enigmatic glycerol" [Polge et al., 1949; Smirnov, 1949] led to the explosion of methods of cryopreservation and types of species cryopreserved and development of the first cryobanks that marked the 1950's. It revolutionized first the cattle industry, than blood transfusion and many others followed. However, while many of them being successful, the method per se remained semi-empirical. However, it has changed with introduction of the 2-factor hypothesis and the equations for the equilibrium slow freezing (minimal intracellular ice formation) by Peter Mazur [Mazur, 1963; Mazur et al., 1972]. Using this truly fundamental approach, Mazur and colleagues in USA and Ian Wilmut in UK were be able to cryopreserve the mouse embryo [Whittingham et al., 1972; Wilmut, 1972]. Since then, slow freezing has been the mainstream of modern cryobiology, and while VF is an 
emerging method that will one day replace SF for many types of cells it has not been done yet: right now SF is an imperative for the majority of cell types.

With the development of Peter Mazur's equations and the 2-factor hypothesis of cryodamage and work of other cryobiologists on slow (equilibrium) freezing in 1960s, it became clear that a particular cell would need its own optimal cryopreservation protocol, which would largely depend on the cell cryobiological and physiological parameters as well as on the type of cryoprotective agents (CPAs) used. Particularly, equilibrium freezing of embryos would require very slow pace of cooling $(0.3-1 \mathrm{OC} / \mathrm{min})$ so the whole cryopreservation process would take several hours. In contrast, for small oblate (flat) ellipsoids such as the red blood cells (RBCs) with an excellent surface-to area ratio, which would allow them to lose water very quickly, the optimal freezing rate of cooling would be in the range of several thousand $\mathrm{OC} / \mathrm{min}$. Thus, if we consider an intermediate cooling rate, say $10 \mathrm{O} / \mathrm{min}$, it would kill oocytes at a very fast rate due to the intracellular ice formation (IIF). But the same cooling rate is too slow for RBC's so they will be dead, due to excessive shrinkage and prolonged degradation ("solute effects"). Yet, for lymphocytes, which are intermediate between oocytes and RBC's that rate would be optimal.

Addition of a CPA shifts the survival curve toward the lower rate and higher survival, which indicates that the CPA protects mostly during suboptimal cooling (see Fig. 2) acting as an osmotic buffer that prevents excessive shrinkage and other "solute effects"[Lovelock, 1953; Mazur, 1970, 1984; Mazur \& Koshimoto, 2002]. The effect of protective action of the CPA is much more pronounced for larger bone marrow cells while small erythrocytes perfectly survive the absence of CPA if cooled fast enough. The optimal concentration, however, is in the same magnitude of 1- $2 \mathrm{M}$. Note that the mechanism of cryoprotective action of CPAs such as glycerol or DMSO at slow sub-optimal cooling rates is absolutely different and works at much lower concentrations than their role as vitrificants ("thickeners") that elevate the viscosity during vitrification (VF). From that standpoint, they should NOT be called "CPAs" but rather "VFAs" in case of VF.

Thus, the optimal ("maximum maximorum") concentration of the CPA (more precisely, the combination of concentration of CPA and rate of cooling) are unique for a particular type of cells. These two concepts are illustrated in Figures 2 and 3. The bottom line is that SF often needs elaborate multi-step protocols, whichrequires special equipment, and it can do exceptionally well, especially if combined with other "tricks" that are specific to the particular species of cells. A good, recent example is the CP of human pluripotent (embryonic and induced alike) stem cells (hESc's and iPSC's respectively). Introduction of i) multi-step freezing, ii) ROCK inhibitors in combination with full cell dissociation, and iii) freezing pluripotent SC's in adherent stage as they are prone to anoikis (cell death after cell are detached from extracellular matrix, [Wagh et al., 2011]) have dramatically increased survival and functionality of human pluripotent cells after SF ([Katkov et al., 2011; Li et al., 2008; MartinIbanez et al., 2009; Mollamohammadi et al., 2009; Stubban et al., 2007; Ware \& Baran, 2007], see Chapter by Martin-Ibanez [Martin-Ibanez, 2012] in this Book). It now highly supersedes various vitrification techniques proposed from time to time [Beier et al., 2011; Reubinoff et al., 2001; Zhou et al., 2004] despite what is claimed otherwise by the authors.

However, the strengths of SF freezing can be its weaknesses as well: it indeed needs elaborative protocols that have to be developed for each new species of cells separately. Secondly, it is difficult to implement for CP of large chunks if tissues, and especially if we are talking about $\mathrm{CP}$ of a whole organ. Yet, the methods and equipment are being developed, see a chapter by Butler in our Book [Butler \& Pegg, 2012]. 


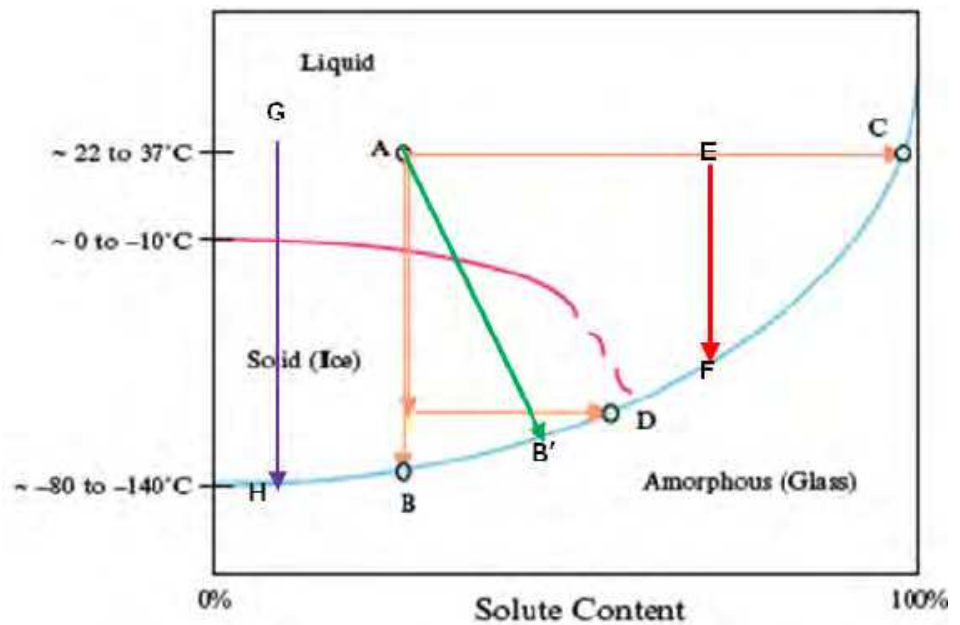

Fig. 1. Five ways of vitrification: A corrected and supplemented phase diagram adapted from [Devireddy \& Thirumala, 2011].

Light Blue line represents the glass temperature $T_{g}$ curve of the sample.

1. Points A-B' (green): slow equilibrium freezing, often called cryopreservation per se. Note, that the solute concentration is dynamically changing during freezing of extracellular ice so the original authors' line A-B (orange) is substituted by A-B' (green).

2. Points E-F (red): equilibrium vitrification (often referred as VF per se). The very viscous solution of the permeable vitrificant (solute) prevents the formation and/or growth of both intracellular and extracellular ice the sample can vitrify without the ice phase practically at any rate of cooling and warming (the E-F is locate at higher concentration than the line of freezing (heterogeneous ice nucleation) shows in a sketchy form in magneto color crosses the $T_{g}$ line at lower concentrations and only two phases, amorphous and liquid, exist on the right side of the $x$-axis.

3. Points G-H (purple): kinetic vitrification that occurs intracellularly at a much lower concentration of the vitrificant or even without permeable VFA. This however, requires much higher rates of cooling and warming so the damaging ice crystals cannot be formed during rapid cooling and re-crystallization (de-vitrification) will be blocked and, and thus, will not damage the cells during very fast warming.

See also other set of phase diagrams in the Fig. 4 and explanation in the text.

4. Points A-D-C (orange): freeze-drying (lyophilization) (not A-D, as originally is stated in [Devireddy \& Thirumala, 2011]). A-D (orange) represents freezing and sublimation of ice (primary drying) followed by elevation of temperature of drying above $\mathrm{OC}$ (secondary drying) D-C.

5. Points A-C (orange): desiccation (xeropreservation) is either vacuum or air/humidity chamber drying where the temperature of drying is always above ${ }^{\circ} \mathrm{C}$ so no freezing phase is present. Note that the temperature drying $\boldsymbol{T}_{d r}$ is always above the glass transition temperature of the sample $\boldsymbol{T}_{g}$ (blue curve) on definition (otherwise, evaporation will not occur due to extremely high viscosity), while for stable storage, the temperature of storage $T_{s t}$ must be below $\mathrm{Tg}$, so the conditions of stable drying are following $T_{s t}<T g<T_{d r}$ (final). Many papers on drying of biological reports $T_{g}$ above $T_{d r}$, which as incorrect, see [Katkov and Levine, $T_{g}$ ] for details and possible explanation of such "paradox". It can explain instability of samples at long storage [Suzuki, 2006] that are often claimed to have $T_{g}+60-70$ OC. 

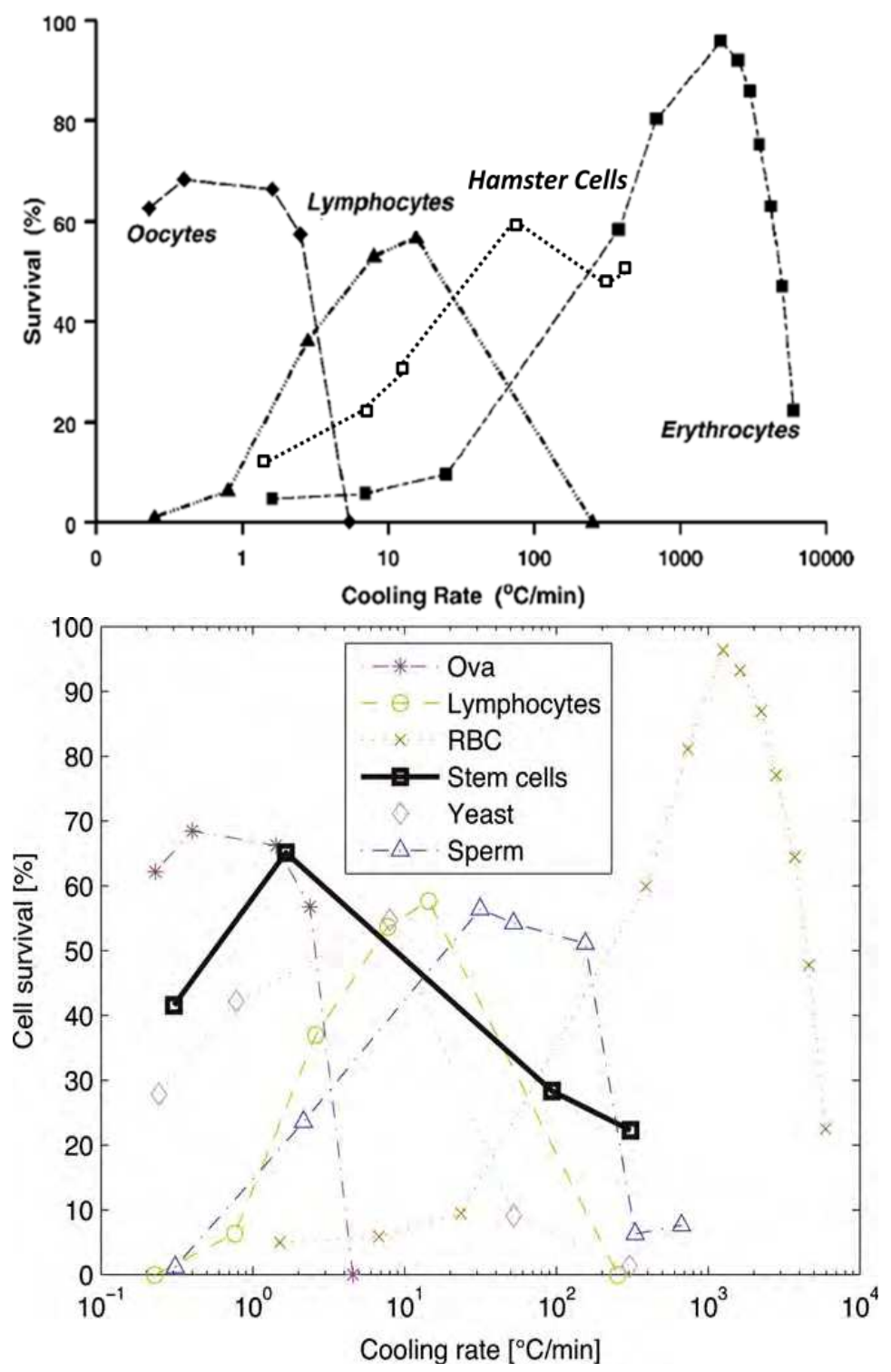

Fig. 2. The two-factor hypothesis of the cryoinjury by Peter Mazur: survival of cells of different size (oocytes $>>$ lymphocytes $>$ hamster cells $>>$ erythrocytes) as function of the cooling rate. Top: Mazur's original graph, adapted from [Mazur et al., 1972; Mazur et al., 2008]. Bottom: Updated for stem cells (large size), yeast moderate) and sperm (slow) in [Cipri et al., 2010]. Note that "slow (sub-optimal) and "fast" (supra-optimal) freezing in this case largely depends on the cells size: e.g., the rate of cooling 10 oC/min is very fast for oocytes (lethal IIF), very slow for erythrocytes ("damage due to the "solute effects") and close to the optimal for lymphocytes. 

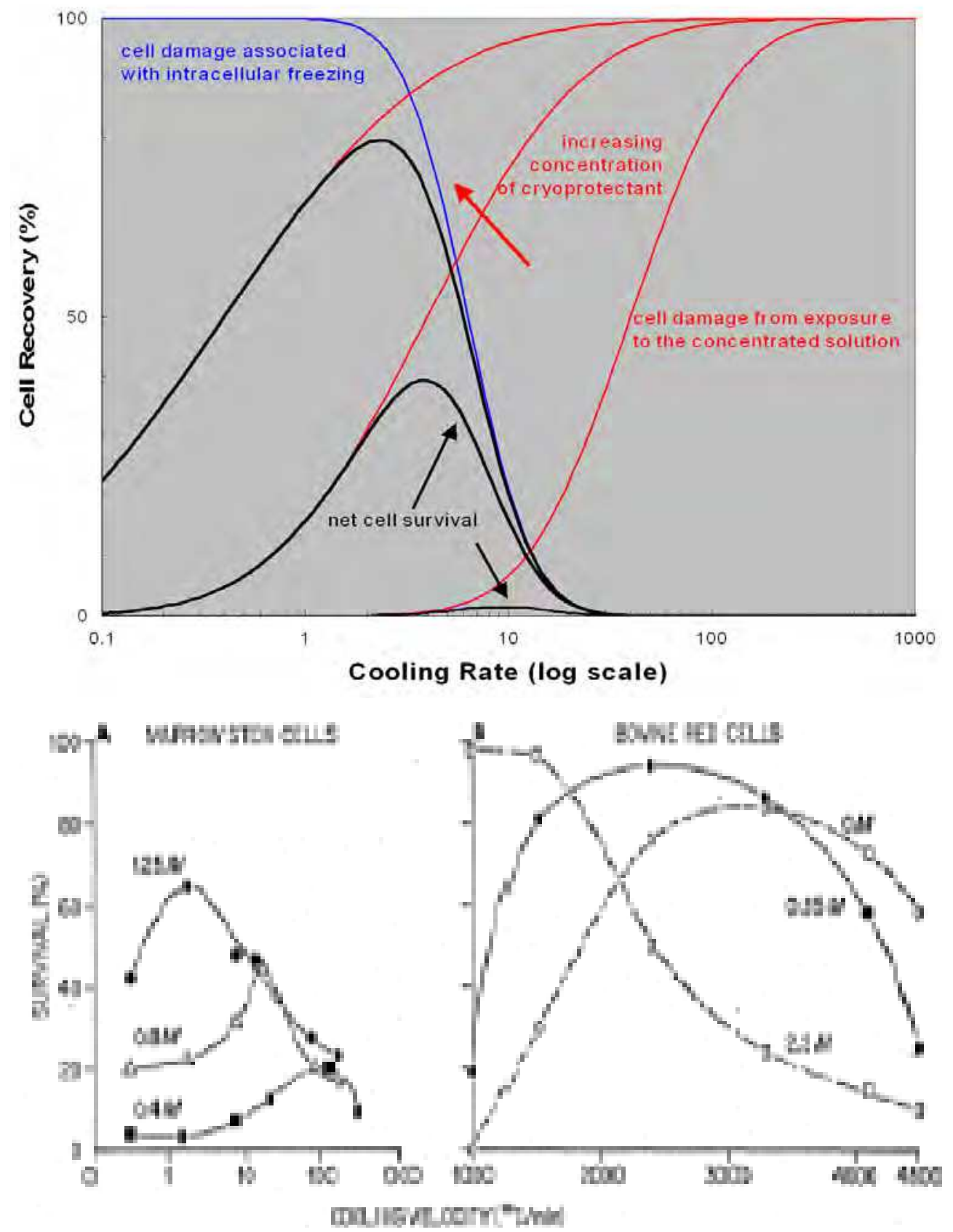

Fig. 3. The role of a cryoprotective agent (CPA) at slow freezing: Survival of cells of different size (marrow cells, the left panel >> erythrocytes on the right) as function of CPA concentration and cooling rate. Adapted from [Mazur, 1970]. 


\subsection{Equilibrium vitrification and "magic" ice blockers: True $21^{\text {st }}$ century medicine or "Fahy's tyranny" and the spearhead of cryonics pseudo-science?}

On the other hand, Greg Fahy and colleagues [Fahy et al., 1984] reported vitrification of the whole organ (i.e. kidney), and later report E-VF of mouse embryo by Bill Rall and Greg Fahy [Rall \& Fahy, 1985]. Since, the fate of VF of these two types of cells and fields split dramatically: E-VF of the whole organ has been essentially stuck in the rut, with very few progress, that has been reported mostly by the Fahy's group per se [Fahy et al., 2009] despite of 25 years of research and substantial amount of financial support that the author received from many sources including taxpayers money. For example, accordingly the Fahy's company with a promising name "21 $1^{\text {st }}$ Century Medicine"(21 CM), posted on their Wikipedia site "In $200421 C M$ received a \$900,000 grant from the U.S. National Institutes of Health (NIH) to develop solutions and processes to improve human heart transplantations" [Wikipedia, 2011a]. Since 1+ million dollars (including previous Phase I) in funding and eight years after that announcement, we have not found any progress report or reliable publication on that topic from the company's scientists in scientific peer-reviewed journal. The vitrification of a heart (even an animal one) is not even close to realization apparently.

The company and its scientific team heavily rely on so called "ice-blockers", chemical substances that block the propagation of ice in big samples cooled very slowly, thus helping vitrification. The company has made progress in the development a pipeline of such reagents. However, they are used mostly as "helpers" to lower the osmotic and chemical toxicity of the enormous concentrations of "common" vitrificants that are necessary for equilibrium (slow vitrification). Whether that approach will ever meet real progress in the remaining 88 years of the $21^{\text {st }}$ century medicine, needs to be seen.

Nonetheless, Dr. Fahy has been very proactive in promoting equilibrium vitrification and denying kinetic one whenever and wherever it is possible. He basically ignores and calls it "quasi vitrification"(e.g., in [Fahy \& Rall, 2007]), and in doing so he contradicts himself within three pages of his own review [Fahy \& Rall, 2007]! In Fig. 1A.1, he placed the start of citations on vitrification of cells and organs. Of course, he starts counting from his publication 1984 totally ignoring the earlier work of Luyet, Boutron, Farrant and other scientists, the very work that Fahy is discussing is a couple of sub-chapters later. Yet, it was he, "the world's foremost expert in cryopreservation by vitrification" (http://en.wikipedia.org/ wiki/Twenty-First_Century_Medicine), who "truly" vitrified cells first. We will come back to this attitude a bit later when we compare E-VF and K-VF. Now, we only say that while his chapter in that book is \#1A, the majority of the next 19 Chapters in fact describe various kinetic vitrification techniques with small size and fast cooling and warming, a typical pattern of K-VF. Few people even mentioned the term ice-blockers, fewer used it in reproduction practice, mainly as "helpers" (see our explanation above).

Who has been truly benefitting from Fahy's and his colleagues work? The people that have been engaged in a pseudo-scientific activity called 'cryonics' (http://en.wikipedia.org/ wiki/Cryonics) They freeze deceased people, or sometimes even just their heads or brains (as did Saul Kent (http://en.wikipedia.org/wiki/Saul_Kent), the founder of the " $21^{\text {st }} \mathrm{CM}^{\text {" }}$ (http://www.biomarkerinc.com/saul_kent_page.html) in the hope that one day the dead will be "resurrected" (?!), or even that the brain can be somehow 'translocated' into a new body. This is at least science fiction and naive beliefs (a type of "transhumanism") and at most a charlatanic snake oil scheme aimed "to skim off big bucks" from the human tragedy so 
it has as much in common with cryobiology as astrology with astronomy or alchemistry with chemistry. Not surprisingly, cryonicists are banned from publication in all scientific cryobiological journals and from the membership in the cryo-societies as their activities have nothing to do with real scientific premises. Yet, they skillfully wrap their messages, post some valid statements, and add some useful websites, for example on physics of glass transition (apparently, they have good physicists among their "disciples") to make cryonics seem like a legitimate science And of course, they cite Fahy's and Brian Wowk's work wherever they can. They actually admit that they buy those ice-blockers from the "21 CM". They are very active in Wikipedia so we can see all biographies of prominent cryonicists, and even much less prominent and rather obscure ones like a former bookkeeper Danila Medvedev in Russia [Wikipedia, 2011c], which the company "KrioRus" proudly announces how many bodies and other parts of humans (including some brains, which they call "Neurovitrification"!), dogs, cats and birds they "vitrified" [Wikipedia, 2011b]. Of course, you can find in Wiki also the biographies of Greg Fahy, Brian Wok, and a detailed description of the "21 CM" company. None of these scientists has ever claimed any of the cryonics beliefs openly (they value their scientific carriers as well as an ability to apply for NIH money, for example, which considers cryonics as a pseudo-science), and we don't imply that those cryobiologists and the current "21 CM" management are "hidden cryonicists". Moreover, the Company's website clearly distances itself from cryonics (http://www.21cm.com/cryobiology.html). However, the fact that cryonics companies and organizations heavily rely on E-VF and ice-blockers as the major method of preservation and future resurrection, their connection, both "ideological, (e.g., hiring a very controversial Ukrainian scientist and former $21 \mathrm{CM}$ employee Yuri Pichugin) and financial (being

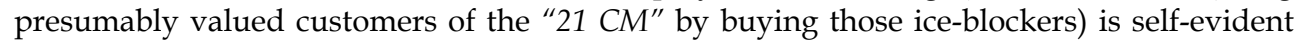
(http://www.cryonics.org/century.html, http://cryonics.org /yuri.html).

\subsection{Modern methods of vitrification of reproductive, stem and other germplasm cells are in the realm of kinetic vitrification, but still many questions remain}

The fate of the second direction of vitrification, which was initiated with the paper by Rall and Fahy [Rall \& Fahy, 1985] on E-VF of embryos, was completely different: it definitely has not been stuck in the rut but rather quite opposite. The use of vitrification for cryopreservation of reproductive cells and tissues has boomed over the last 20+ years since that seminal paper was published. However, the modern methods of VF of oocytes, embryos, sperm, ovarian and testicular tissue are in fact the varieties of kinetic vitrification. Elaborative multi-step protocols of the addition of VFA's before VF and elution of them after warming have been developed to decrease the toxic and osmotic effects of vitrification. Some of those methods are covered by other Chapters or our Books 1 and 2 and by the above-mentioned excellent book by Tucker and Lieberman [Tucker \& Liebermann, 2007]. Up to now, a vast variety of carriers has been developed as well. They are summarized in an excellent review by Saragusty and Arav [Saragusty \& Arav, 2011] and is reproduced on Fig. 4.

While there is still a debate over what is better for a particular cell type or species, slow freezing or kinetic vitrification, the latter one is gaining ground, particularly for VF of oocytes, thanks to ART scientists and practitioners such as Kuwayama, Vajta, Sheldon, Liebermann, Tucker and many others. Note however, that sometime that "cold war" may 
erupt and evolve into a "hot war" when it comes to which set of VF media, the protocol, and the carrier are better. Thus, while being faster and simpler than slow freezing (though much farther from automation and "full proof"), vitrification at this moment has been struggling basically with the same problem as the SF has been plagued with: each type of cells, the carrier, and VF media need own protocol, and very often a VF media that work for open carries are too diluted for closed carriers, while using open carriers raises concern of contamination etc. The bottom line is that kinetic vitrification as it is now, offers a vast variety of the methods, that have to be checked and adjusted when a new type of cells of/or new species of animals are in consideration.

As we can see later, our experience with vitrifcation led us to conclude that it might change soon, but before moving further, we have to look in more detail at the distinction and principal differences between equilibrium and kinetic vitrification from the standpoint of thermodynamics. In other words, we have to look at the supplemental phase diagram, or as we call it here, the "Fahy's diagram" as it was first published and explained in detail from the cryobiological audience by Fahy and colleagues [Fahy et al., 1984].

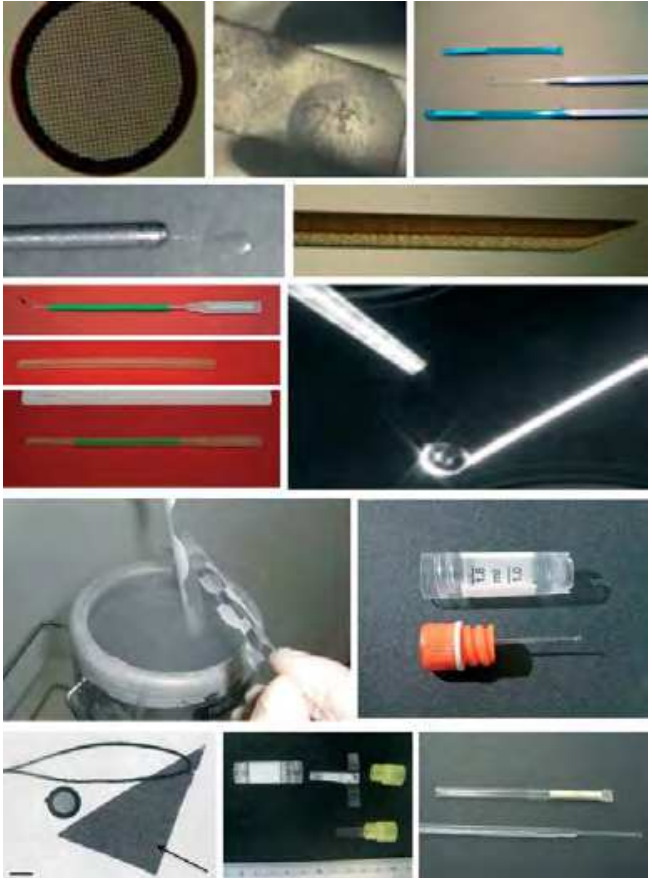

A
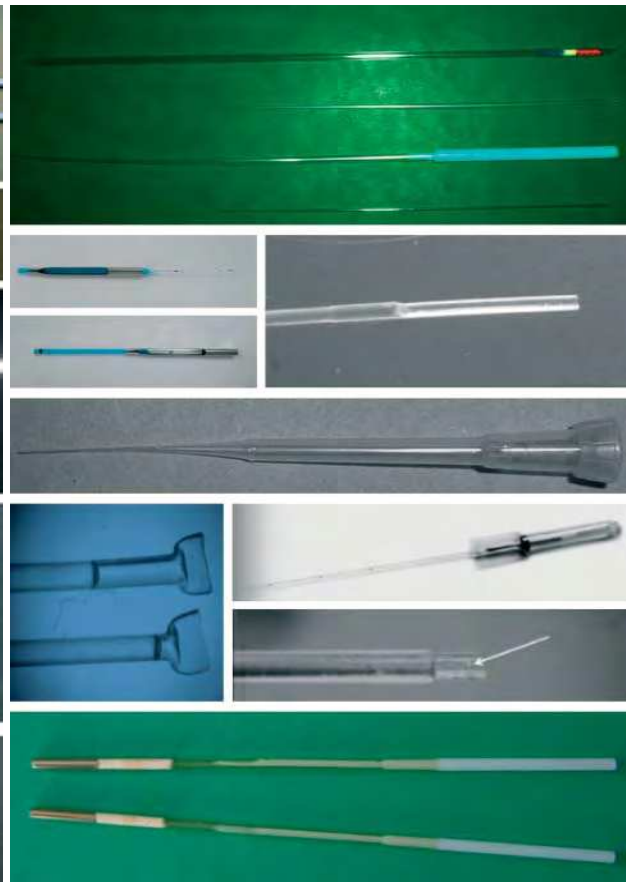

B

Fig. 4. Vitrification carrier systems [Saragusty \& Arav, 2011].

A: surface carriers. First raw: electron microscope grid, minimum drop size; Cryotop; Second raw: Cryoloop, Hemi-straw; Third raw: Cryoleaf, fiber plug, Fourth raw: direct cover VF, VF 
spatula; Fifth raw: nylon mesh - arrow points at the nylon mesh, plastic blade, Vitri-Inga. B: tubing carriers. First raw (top to the bottom): $0.25-\mathrm{mL}$ mini-straw, $0.25 \mathrm{ml}$ mini-straw, Open-pulled straw (OPS), Superfine OPS (SOPS), Flexipet-denuding pipette (170 $\mu \mathrm{m}$ end hole); Second raw: CryoTip (opena and loaded), high-security vitrification device; Third raw: pipette tip, Fourth raw: sealed pulled straw (left), (Cryopette (top right), Rapid-I (right-bottom); Fifth raw: JY Straws.

See [Saragusty \& Arav, 2011] for more details and references.

\section{Equilibrium vs. kinetic vitrifcation; Evolution of the "Fahy's" phase diagram}

This sub-chapter discusses in detail the phase diagram ("Fahy-Rall" vitrification diagram). We will also discuss using this diagram the two basic and reciprocal ways of achieving VF, which can be done: i) by cooling and warming at relatively moderate rates but very high concentrations of exogenous (and often toxic) vitrification agents/enhancers (VFAs), which is defined as equilibrium VF and ii) by increasing the rate of cooling with a few or not at all exogenous VFAs present, which we refer as kinetic VF. We will also emphasize that the border of "non-achievable" and "achievable" VF that was once set up by Fahy is arbitrary and largely depends on the currently achievable rates of cooling and warming.

Fig. 5A depicts the original diagram published by Fahy et al in 1984 [Fahy et al., 1984]. The diagram is divided in 4 distinctive zones. Zone IV is the equilibrium VF, when it occurs at any practical rates of cooling and warming as it lies to the right of the junction of $\boldsymbol{T}_{m}$ (i.e., no ice forming during cooling) and $T_{d}$ (no de-vitrifcation during warming). It is basically the zone where the line E-F on Fig. 1 is drawn but with the notion that $T_{g}$ in the Fahy's diagrams (apparently, for glycerol) lies substantially lower than in Devireddy's diagram ( $T_{g}$ of a fully dehydrated sample is well above $0{ }^{\circ} \mathrm{C}$ while $T_{g}$ of glycerol is in range of $-90{ }^{\circ} \mathrm{C}$ and below [Pouplin et al., 1999]. For $\boldsymbol{T}_{g}{ }^{\prime}$ s of some popular vitrificants see Table 1 in [Katkov \& Levine, 2004]. Zone III is the zone when vitrification occurs. The left border is the junction of $T_{h}$ (showed in dotted line as it is hardly to estimate $T_{h}$ of very viscous samples) and glass transition curve $T_{g}$ and it occurs at concentrated $C_{v}$ 's, the minimal concentrations where equilibrium vitrification during cooling occurs at practically any speed. However, such concentration still may produce de-vitrification during re-warming as the devitrification curve $T_{d}$ crosses the melting (equilibrium warming) curve at the critical concentration of devitrification $C_{d v}$. Thus, this Zone III is the zone where warming must be done fast.

Zone II, called by Fahy and colleagues at that time (!) "doubly unstable" lies at concentration below $C_{v}$. At those concentrations, both cooling and warming must be done fast to avoid ice formatting and devitrification respectively. That is what we call kinetic vitrification as it deals with the speed of cooling and re-warming rather than with the equilibrium values. It means that the border between that Zone II, where vitrification is achievable with the Zone I, where successfully vitrification is impossible at any "reasonable speed" of cooling and warming largely depends on the rate of that cooling and warming: it is reciprocal to the $C_{v}$ and $C_{d v}$ so they move to the left into the area of the lower concentrations.

Thus, there are 2 basic and reciprocal ways of achieving VF: i) by raising the concentration, and as result, the viscosity of the intra- and extracellular milieu at relatively moderate and even slow rates of cooling but very high concentrations VFAs, 
which is defined as equilibrium VF and ii) by increasing the rate of cooling with a few or not at all exogenous VFAs present so deleterious intracellular ice formation is not achieved due to lack of time for growing ice crystal nuclei (kinetic VF). Note that the border between "non-achievable" and "achievable" VF (Zones I and II) that was once set up by Fahy is arbitrary and as we said, largely depends on the currently achievable rates of cooling and warming.

The position of the borders between the zones also depends on the glass transition temperature of the solute $\left(T_{g}\right.$ curve). As we mentioned above, Fahy et al. had considered a permeable vitrificant with very low $T_{g}$ in range of $-90{ }^{\circ} \mathrm{C}$ (glycerol). In the paper on vitrification of sperm that we published in 2003, we hypothesized that $T_{g}$ of the intracellular milieu could be much higher, so the $\boldsymbol{T}_{g}$ of the intracellular exogenous solute would go much above of $\boldsymbol{T}_{g}$ of glycerol. We published a review in 2006 [Katkov et al., 2006] (the abstract was presented much earlier in 2003 [Katkov et al., 2003]) with that concept superimposed onto Fahy's diagram. This concept and an explanation as to why we could vitrify sperm at much less or no exogenous vitrificants at all is shown in Fig 5B. We emphasized that the $T_{g}$ of a internal vitrificants can go very high, so the border between Zones I and II can be shifted substantially to the left so the successful vitrification (straight blue line) is achievable even the extracellular milieu has no glycerol.

This explanation (and at lesser extent the experimental data published at that time per se) had been dismissed both by Fahy and by other prominent cryobiologists, most notable of them would be Stan Leibo. They either called it "quasi-vitrification" or ignored that such work was published (due to the fact that it was not referred at PubMed, even though the leading author had distributed its copies among numerous scientists in the field). The striking example is the Fahy's chapter [Fahy \& Rall, 2007] where he spent a great deal of time bashing kinetic vitrification, giving intricate details as to how its first scientists had failed lately to implement $\mathrm{K}-\mathrm{VF}$ in practice. In regards to our work, he simply ignored that paper even existed, even though it had been sent it to him and we discussed it with him [Dr. Fahy] in meetings.

So, the "contemporary vitrificators" ignored mentioning the paper and notion of kinetic vitrification at very low concentration of the extracellular solute. That however, did not mean they had not learned or gained from it. Neither could they ignore the booming success of K-VF in the assisted reproduction field, which we mentioned above. The whole set of innovation was aimed to cool and warm cells faster, which allowed the ART practitioners to move away from the humongous concentrations of DMSO, EG, PG or glycerol, which would be necessary for equilibrium VF. So, that was actually reflected in the very same chapter published in 2007 [Fahy \& Rall, 2007] as it presented a Fahy's diagram with some interesting and key changes in comparison to the publication in year 1984 (Fig. 5C). We deliberately superimposed those changes on the original Fahy's diagram [Fahy et al., 1984].

First, the words "doubly unstable" have been eliminated and it made sense because $99 \%$ of publications on vitrification of oocytes and embryos have been done at concentrations that exactly represented the "doubly unstable" Zone. That would not make all people who have successfully and stably frozen their precious happy to realize that they actually worked in the "double instability" zone (and which is not correct anyway: the vitrified cells are stable at temperatures below of their glass transition, i.e., well below the $\mathrm{LN}_{2}$ temperature). 
Secondly, the authors of the chapter shifted the border between "achievable" and "nonachievable" vitrification (Zones I and II) to the left. It was a small concession to the reality, people have been successfully vitrifying oocytes and other "watery' cells with substantially less concentrations than $40 \%$, but yet it reflects the general "drift to the left", so to speak.

Most importantly in our opinion is that the notorious "killing darts", which marked the "unsuccessful vitrification" in the Zone I on the original Fahy's diagram in 1984... suddenly disappeared in a newer version. It means that the authors allowed (at least theoretically) the

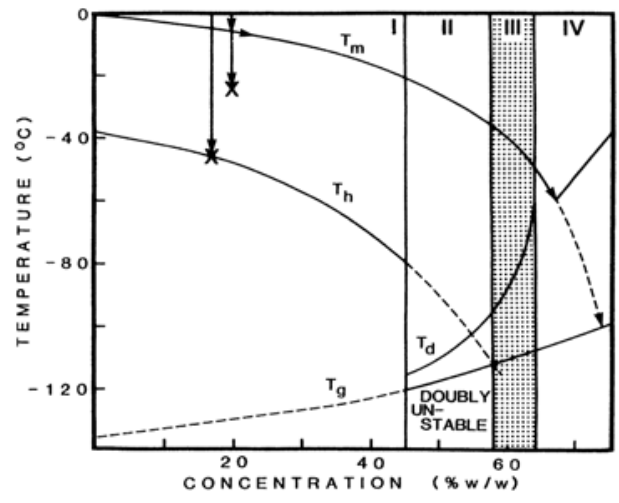

A

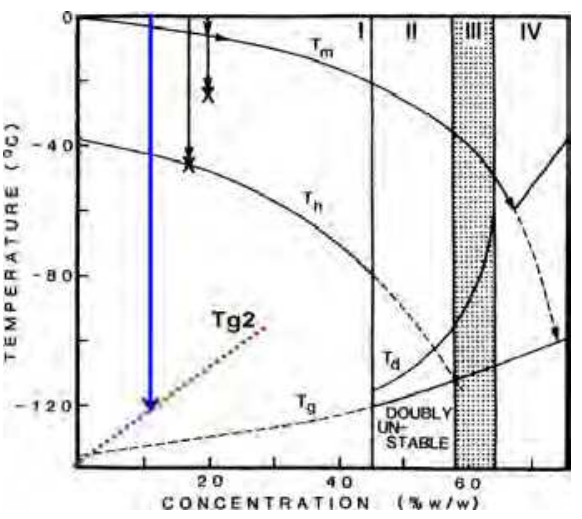

B

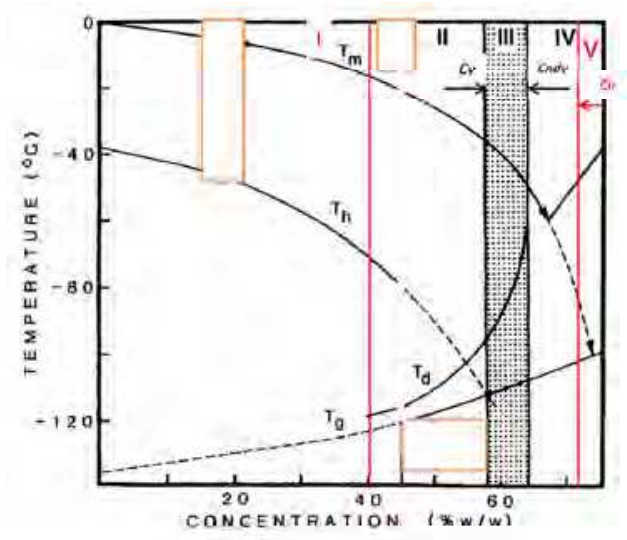

$\mathrm{C}$

Fig. 5. A (top): original diagram published Fahy et al. in 1984 [Fahy et al., 1984]. The diagram is divided in 4 distinctive zones. Zone IV is the equilibrium VF, when it occurs at any practical rates of cooling and warming as it lies to the right of the junction of $T_{m}$ (i.e., no ice forming during cooling) and $\boldsymbol{T}_{\boldsymbol{d}}$ (no de-vitrifcation during warming) it is basically the zone 
when the line E-F on Fig. 1 is drawn but with the notion that $T_{g}$ in the Fahy's diagrams (apparently, for glycerol) lies substantially lower than in Devireddy's diagram ( $T_{g}$ of fully anhydrated sample is well above ${ }^{\circ} \mathrm{C}$ while for glycerol $T_{g}$ depicted on this diagram is in range of $-90{ }^{\circ} \mathrm{C}$ and below [Pouplin et al., 1999]. For $\boldsymbol{T}_{g}{ }^{\prime} \mathrm{S}$ of other popular vitrificants see Table 1 in [Katkov \& Levine, 2004]. Zone I is the zone of "non-achievable" VF, Zone II is kinetic VF marked as "doubly unstable", and Zone III is an intermediate zone where devitrification must be avoided while VF is achievable at slow rates. Note two "killing darts" in Zone I that indicate ice crystallization (vitrification is not achieved).

B (middle): Fahy's diagram supplemented by us in 2006 [Katkov et al., 2006] with the notion that the border between Zones I (unsuccessful VF) and II (successful kinetic VF) in diagram A is arbitrary and can be moved far left to the area of very low concentrations of external VFA's (or no VFA not at all as in case of human sperm). The blue line indicates successful kinetic VF, it is analogous with the G-H line on Fig. 1.

C (bottom): Fahy's diagram, version 2007 depicted in [Fahy \& Rall, 2007] but superimposed by us on the original diagram A. Note the following notable changes: i) "disappearance of words "doubly instable"; ii) shifting the border between zones I and II to the left; iii) disappearance of the "killing darts" in Zone 1; in addition of Zone V (E-VF achievable even with a introduction of exogenous ice: propagation of the ice is stopped).

See the major text for further explanation.

blasphemous idea that vitrification could occur at any concentration of the solute, however low it might be. And it is true, even the pure water can also be vitrified, though the rate of vitrification must be in range of tens to hundreds of millions ${ }^{\circ} \mathrm{C} / \mathrm{min}$ [Angell, 2004]. We can only speculate where all those Zones would go in that case. Apparently, they would all disappear! Finally, Fahy and Rall made two crucial concessions in their text (probably, insisted by Bill Rall taking to the account his vast experience and knowledge of the ART field), which we cite below in full:

- "For the small samples often used in reproductive cryobiology, it becomes important that $\boldsymbol{T}_{h}, \boldsymbol{T}_{g^{\prime}}$ and $\boldsymbol{T}_{d}$ are all rate dependent (i.e,. $\boldsymbol{T}_{\boldsymbol{h}}$ will go down, $\boldsymbol{T}_{g}$ will go up, and $\boldsymbol{T}_{\boldsymbol{d}}$ will go up as the rate of change of temperature increases) because extremely high cooling and warming rates are feasible."

- "However, Figure 1A.5 [depicts relationships between the critical cooling rate of vitrification and concentration of the vitrificant, I.I.K.] is based on pure permeating cryoprotectants in water and does not take into account the effects of the carrier solution (see below) or additives such as serum or sucrose, nor does it take into account the effect of concentrated intracellular protein in shrunken cells or the naturally low water content of cells like spermatozoa" [of course, no mentioning of our work whatsoever!]

Those two citations exactly explain how kinetic vitrification works without even mentioning it! While we are quite accustomed to the that style of ignoring "inconvenient" publications from several prominent cryobilogists and pushing their explanation aside the facts that "adjusted" (with the reality) Fahy's curve together with the two statements above clearly indicate that even as the staunchest orthodox proponents of equilibrium ("right") vitrification as Dr. Fahy could not ignore the facts and explanation why and how the kinetic one is working and dominating the scene now. Apparently and evidently they learned from our publication, as well as from the publications of others. 
There are other peculiar similarities between that chapter and some of our earlier papers, such as use of the equation for determination of the viscosity of the solute near $T_{g}$ [Katkov \& Levine, 2004] and storage below and above $\boldsymbol{T}_{g}$ of the sample [Katkov et al., 2006]; we would encourage our readers to compare our work and the Fahy's review with the notion that WLF relationship for viscosity near $T_{g}$ in our work is substituted by an equivalent VTF equation in the Fahy's chapter (see Appendix 1).

In conclusion, of these sub-chapters, it is evident that the kinetic way dominates the present art of vitrification and all efforts are moving to the direction of increasing speeds and decreasing concentrations (see "Race for The Pace" below). On the other hand, the future of equilibrium vitrification even in the field where it cannot be substituted by K-VF such as organ CP (but can be done with precision SF as described in a Chapter by Butler and Pegg in this Book [Butler \& Pegg, 2012]), remains largely unclear.

\section{Kinetic vitrification of sperm: why some species have while others have not been vitrified?}

Now, as we are fully equipped to discuss the core topic of the Chapter, let us refresh the turn of (relatively) recent events related to the kinetic VF of spermatozoa.

\subsection{A turn of the helix: The Isachenkos' experiments on vitrification of human sperm}

As we mentioned in the Introductory sub-chapter, 1, after earlier attempts to vitrify sperm with contradictory results, the findings of the cryoprotective role of glycerol and other CPAs at slow freezing moved the field of cryopreservation of spermatozoa from early attempts of K-VF toward E-SF. It has been successfully applied to many types of sperm, yet somewhere in 1990s, the data started accumulating that suggested that glycerol, DMSO and other permeable CPAs might adversely affect the genetic and especially epigenetic fabric of spermatozoa. At the same time, several Japanese groups had successful CP of very sensitive mouse spermatozoa without any permeable CPA but with $18 \%$ of impermeable raffinose (a 3-ring sugar) and a mixture of proteins (skim milk) [Okuyama et al., 1990; Tada et al., 1990; Yokoyama et al., 1990]. It worked so exceptionally well, that the Mazur's group, which had originally cryopreserved mouse sperm with glycerol [Mazur et al., 2000] (though found that it can be indeed chemically toxic to the sperm [Katkov et al., 1998]) finally also reported that fast immersion of mouse spermatozoa into liquid nitrogen without any CPA worked perfectly [Koshimoto et al., 2000]. In any case, those data had inspired Evgenia and Vladimir Isachenko to freeze human sperm in tiny pellicles by plunging those "cryogenic loops" without any CPA whatsoever. They published their findings in 2002, and a year later, the explanation why it worked was followed [Isachenko et al., 2003; Nawroth et al., 2002]. That marked the "second wind" in the kinetic VF of spermatozoa. The history of the development is described in numerous papers [Isachenko et al., 2004a; Isachenko et al., 2008; Isachenko et al., 2004b; Isachenko et al., 2005] and several reviews by the authors [Isachenko et al., 2007; Isachenko et al., 2010; Katkov et al., 2007] and briefly touched in this Book in Chapter 2 [Isachenko et al., 2012]. The method has been involved from a cryo loop (pellicle) through droplets in $\mathrm{LN}_{2}$ to quite elaborated "aseptic technology". Some of the carriers used by the Isachenkos at different stages are shown in Fig. 6. 


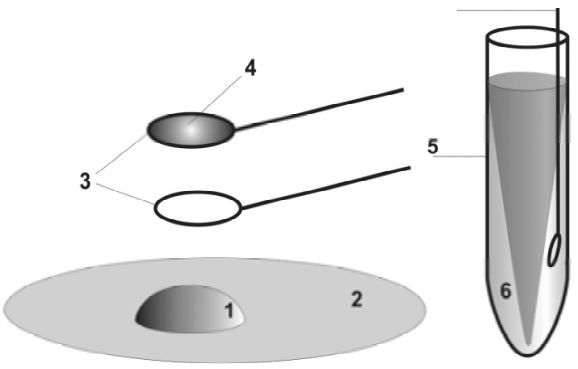

A

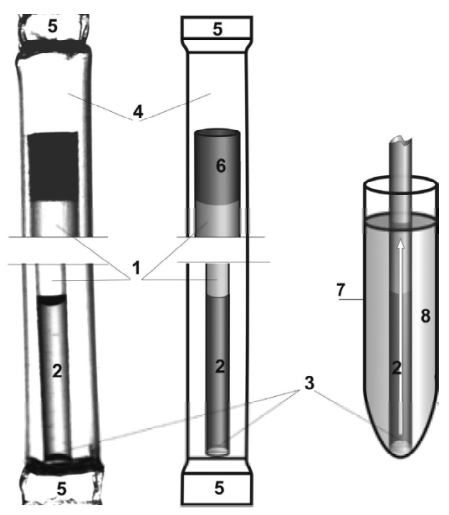

C

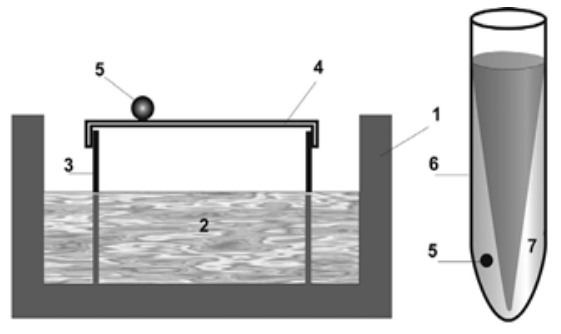

B

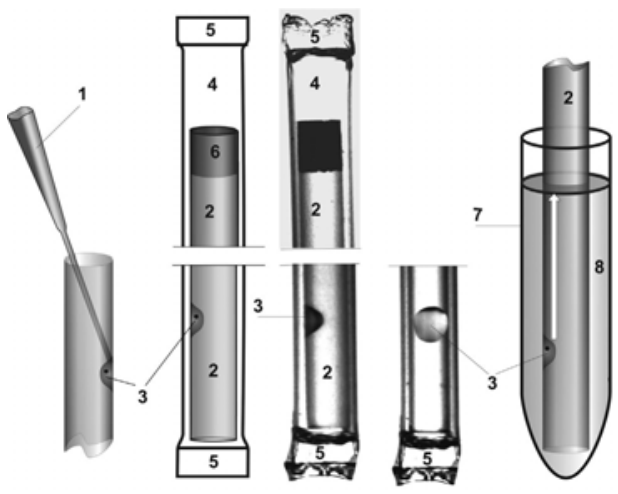

$\mathrm{D}$

Fig. 6. Different techniques for kinetic vitrifcation of human sperm developed by the Isachenkos and colleagues: A: copper or nylon cryo loop (pellicle); B: a modification of a droplet technique; C; open-pulled straw; D; straw-in- straw. See [Isachenko et al., 2007] for details.

The method and the scientist themselves were first dismissed, than ignored, than ... ignored again. Table 1 represents just two examples when the Isachenkos published their paper, and other cryobiologists, who came to the same conclusions, namely:

- There is no proof of the absence of vitrification inside the sperm even at quite slow cooling [Morris, 2006]; the role of intracellular ice in the death of fast cooling mouse sperm is also questioned in [Mazur \& Koshimoto, 2002].

- $\quad$ Some cells can be vitrified in "diluted" solutions at relatively slow rate of cooling but very fast warming is essential for kinetic VF [Mazur \& Seki, 2011]

Thus, both cryobiologists have reported similar findings as the Isachenkos observations, but they unfortunately fell short of mentioning Isachenkos in their own publications and presentations (e.g., in Cryo-2010 in Bristol), which might have made looking their observations (that were solid, of course) for an unfamiliar reader as "pioneering" or even as "a new paradigm for cryopreservation by vitrifcation" [Mazur \& Seki, 2011]. The argument "that paper by the Isachenkos et al. was not citable because the effect of the warming rates was not 


\begin{tabular}{|c|c|}
\hline $\begin{array}{l}\text { V. \& E. Isachenkos and I.I. Katkov: } \\
\text { Factors that may enhance intracellular } \\
\text { vitrification of human sperm: } \\
\text {...Cells naturally contain high } \\
\text { concentrations of proteins, which help in } \\
\text { vitrifcation... this would enhace both the } \\
\text { viscosity and Tg of the intracellular cytosol of } \\
\text { permatozoa. [Isachenko et al., 2003]. }\end{array}$ & $\begin{array}{l}\text { John Morris: } \\
\text { - "It is generally assumed that the intracellular } \\
\text { environment of sperm has a low water } \\
\text { content coupled with high protein levels. } \\
\text { These data demonstrates that it } \\
\text { heterogeneous nucleation sites are absent in } \\
\text { that intracellular vitrification can occur:" } \\
\text { (CRYO-2010). } \\
\text { - "We demonstrate that the high } \\
\text { intracellular protein content together with } \\
\text { the osmotic shrinkage associated with } \\
\text { extracellular ice formation leads to } \\
\text { intracellular vitrification of spermatozoa } \\
\text { during cooling" (Morris et al, 2011, } \\
\text { Cryobiology, 64:71-80). } \\
\text { - "The results described in this article } \\
\text { suggest that it is now appropriate for new } \\
\text { models to be developed that exclude the } \\
\text { formation of intracellular ice" [Morris, 2006]. }\end{array}$ \\
\hline $\begin{array}{l}\text { V. \& E. Isachenkos and I.I. Katkov: } \\
\text { Crucial role of fast warming } \\
\text {... As a result, we can speculate that we were } \\
\text { able to achieve intracellular vitrification of the } \\
\text { human spermatozoa even at such a low range } \\
\text { cooling rate. ... However, as we discuss below, } \\
\text { our method of instant thawing seemed to } \\
\text { prevent cell damage even after relative slow } \\
\text { freezing in liquid nitrogen vapor. [Isachenko } \\
\text { et al., 2004b] }\end{array}$ & $\begin{array}{l}\text { Peter Mazur and Shinsuke Seki: } \\
\text { WARMING rate is much more critical in } \\
\text { "diluted" vitrification solutions than the cooling } \\
\text { rate (CRYO-2010), [Mazur \& Seki, 2011] }\end{array}$ \\
\hline
\end{tabular}

Table 1. Comparison of statements published by Isachenkos et al in 2003-4 and by other scientists reported in 2010 on Cryo-2010 in Bristol, UK and other publications.

thoroughly investigated" makes sense in the matter of describing a particular technique/ protocol but it does not hold water when the claim of a "new paradigm" in vitrification was put on the table seven years after the Isachenkos' paper, with essentially the same claim that had been published [Isachenko et al., 2004b]. That new paradigm was indeed established but it was done in 2002-4, not in 2010-11!

Note that the role of ultrafast warming during kinetic vitrification had been known at some extend before so neither of the authors (the Isachenkos or Mazur \& Seiko) can claim the absolute priority. In case with the crucial role of endogenous proteins and other high molecular weight components for the intracellular kinetic vitrification of spermatozoa, Katkov and colleagues clearly presented this idea (and indirect proof of it) in 2003. Therefore, any attempts to completely ignore that fact by Morris and colleagues and to position themselves as "pioneers" of this idea much later can be considered as blunt plagiarism. 


\subsection{Kinetic vitrification of sperm of other vertebrates: history of success and stories of failure}

As we have mentioned, kinetic VF of human sperm in all its varieties shown on Fig. 6 seemed to be working equally well; however, when we tried the "droplet method" described in [Isachenko et al., 2008] $(20 \mu \mathrm{L}$ droplets of swam-up washed sperm supplemented by $0.25 \mathrm{M}$ sucrose) on model animals (rodent spermatozoa, the results (Figs. 7) were not so pronounced. So, while it worked well for human sperm, the droplet kinetic VF did not work so well for mouse sperm, and it worked poorly (at a much lower survival rate than conventional slow freezing) on rat sperm. Note that both rats and mice sperm have larger and apparently more watery heads.

But still, the Isachenkos' method worked in general so Celltronix and Kharkov Zoo launched 2 field expeditions (with the participation of a Moscow Zoo's specialist) for freezing polar bear (Ursus maritimus) sperm (in a distant Russian zoo) and sperm of gyrfalcons (Falco rusticolus), golden eagles (Aquila chrysaetos) and Eastern imperial eagles (Aquila heliaca) in the Russian Raptor Breeding Center Galichya Gora near Voronezh.

For the polar bear, for which sperm, to our knowledge, had not been frozen yet, the basic slow protocol developed for spectacled bear (Tremarctos ornatus) [Erokhin et al., 2007] was used. That protocol worked quite poorly, vitrification protocol was even worse.

For the all 3 raptor species, gyrfalcon, the golden and the imperial eagles, slow freezing (using the slow freezing protocol in [Blanco et al., 2000]) worked very poorly in our hands despite the fact that artificial insemination with fresh sperm is a routine and successful procedure in that Center. And finally, kinetic vitrification using the Isachenko's "droplet" method failed completely.

After several sleepless nights of thinking what went wrong besides our insufficient experience with freezing the raptor sperm (my counterpart had frozen crane sperm before), difficulties related to small volume and a lot of fecal particles and urine in sperm, I.I. Katkov realized that the sperm of those species was fundamentally different in geometry from that of human sperm: their heads were much larger, and they looked much more watery, less condensed than the compact human portions. The rodent sperm heads were also relatively large, but those species, where we failed, the heads apparently contained much more water and presumably less so called "inactive osmotic volume", which means the concentration of internal proteins, sugars, nucleotides and other "internal endogenous vitrificants" was much lower in the polar bear spermatozoa, and especially in the sperm of the raptors. And according to the thermodynamic of the glassy state, as lower concentration of vitrificants the faster you need to cool the cells. From the personal communication with the Isachenkos several years before, it was known that kinetic vitrification of oocytes and embryos without cryoprotectants had been failed completely even with the smallest drops. And those cells have the ratio internal vitrificants: water about 7-9 lower than in human sperm as its osmotically active volume (i.e. water per se) is about $75 \%$, while in human sperm it is only $25 \%$. That meant that we just did not have sufficient cooling speed to vitrify those species!! That crystallized the hypothesis that if we would cool it fast enough, faster than the critical rates of cooling and warming for the most watery cells, we can vitrify all cells with the same protocol. That is how the concept of the Universal Cryopreservation Protocol was born (published first in the "Embryomail" in the spring of 2010). 

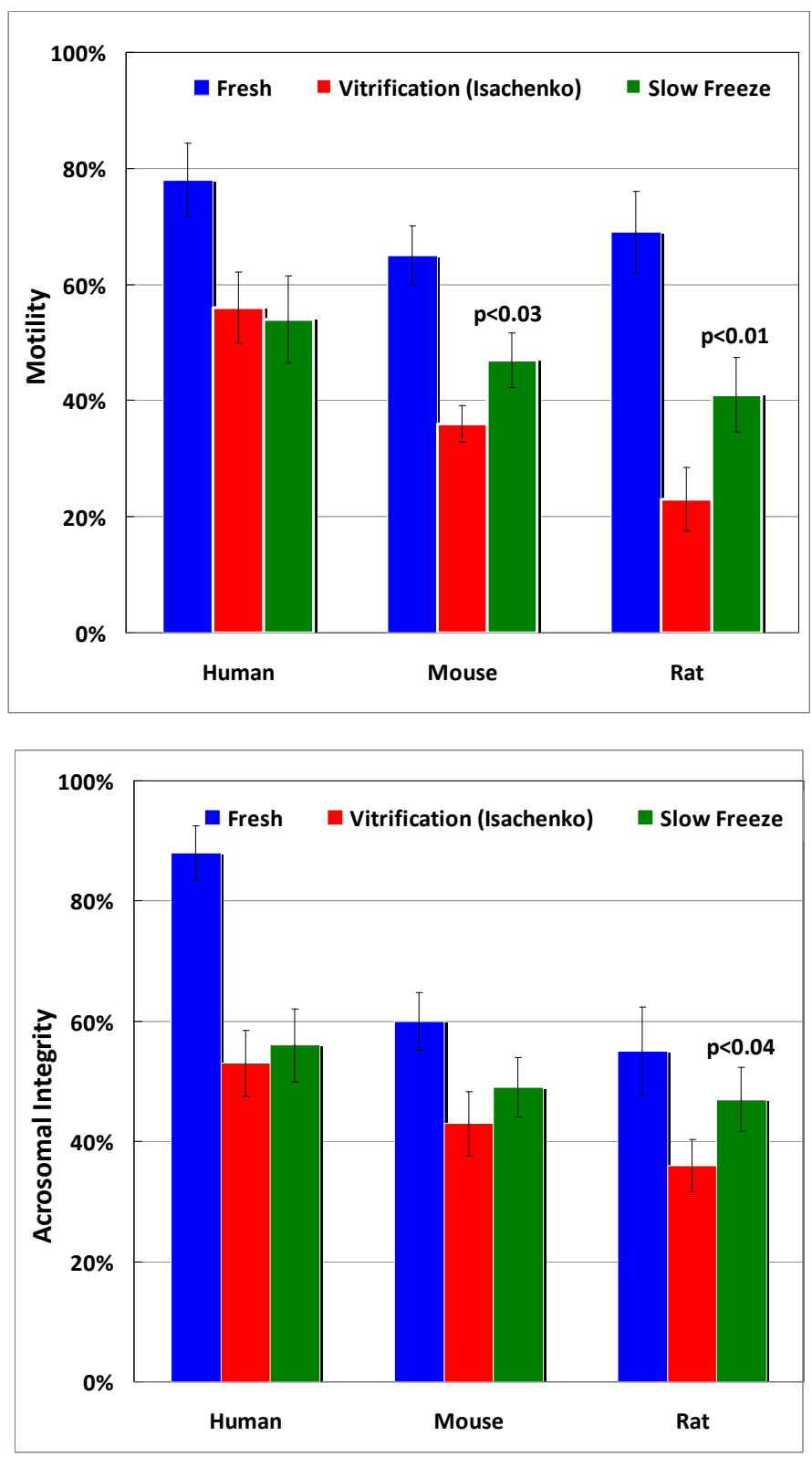

Fig. 7. Progressive motility (left) and acrosomal integrity (right) of 3 species of sperm frozen by conventional slow-freezing protocols in the media customized for different species (green) and by an identical protocol of vitrification [Isachenko et al., 2008] by quenching droplets in PBS containing 20\% human serum albumin (HSA) and $0.25 \mathrm{M}$ sucrose (red) directly into $\mathrm{LN}_{2}$. Two methods of cryopreservation are compared. 

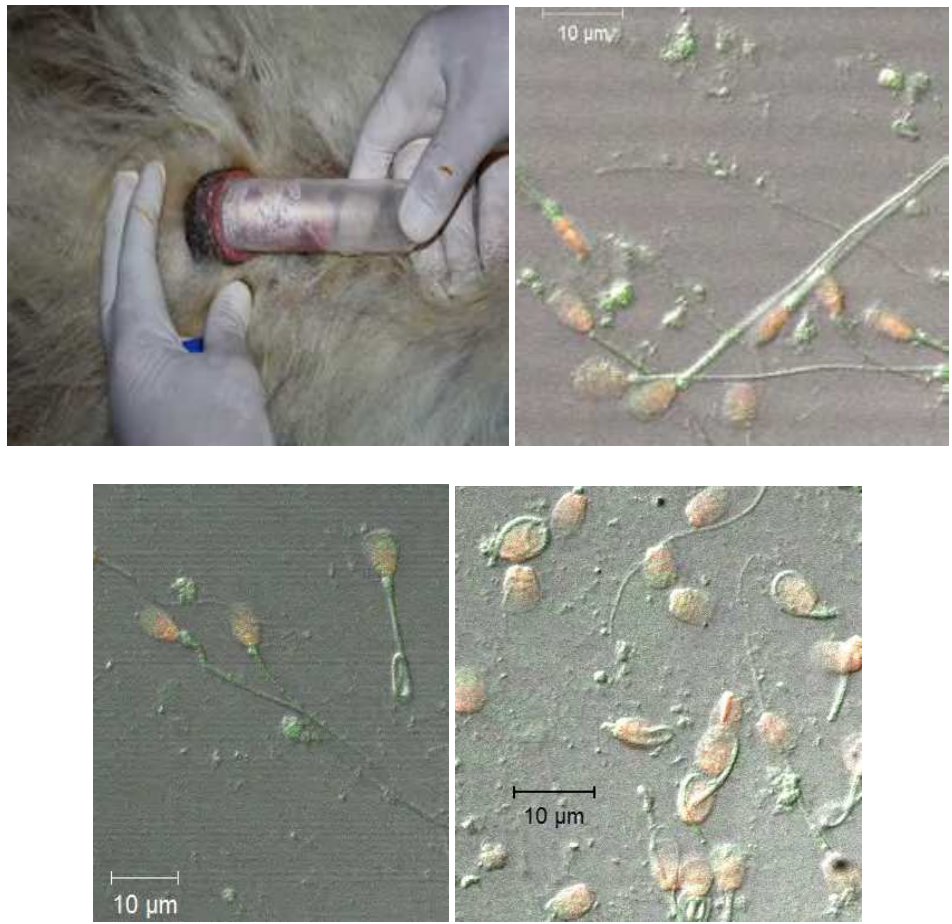

Fig. 8A. An attempt to vitrify sperm of the polar bear, from left to right: sperm retrieval; fresh; slow frozen; and vitrified sperm. Slow frozen sperm protocol worked poorly, kinetic VF failed.
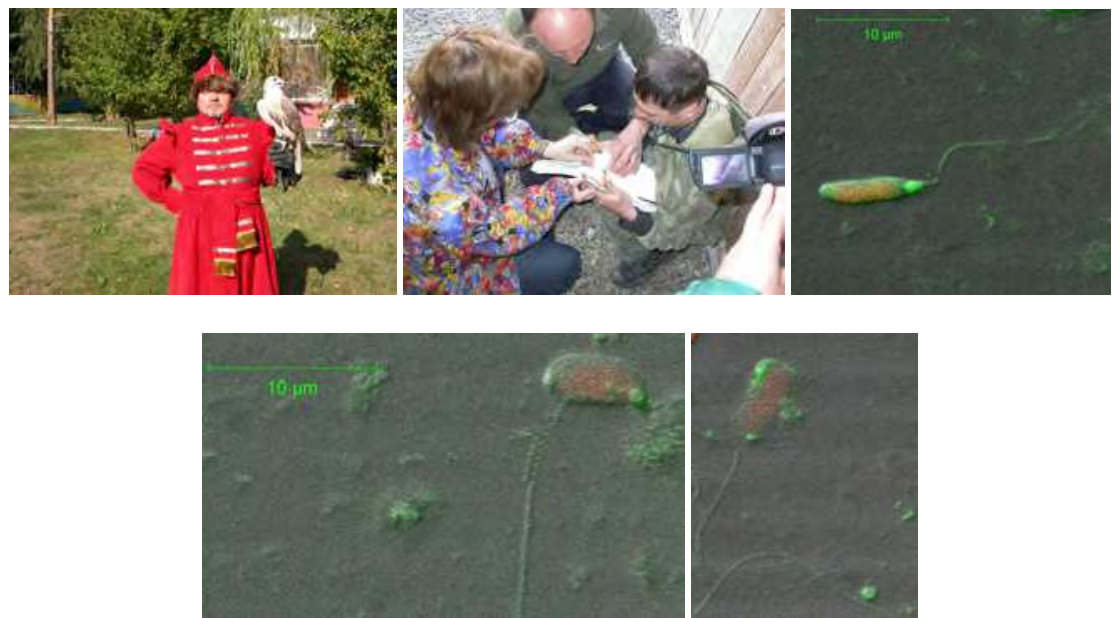

Fig. 8B. An attempt to vitrify sperm of the gyrfalcon, from left to right: I.I.K. with the bird; sperm retrieval process; fresh; slow frozen; and vitrified sperm. Slow frozen sperm protocol worked poorly, kinetic VF failed. 

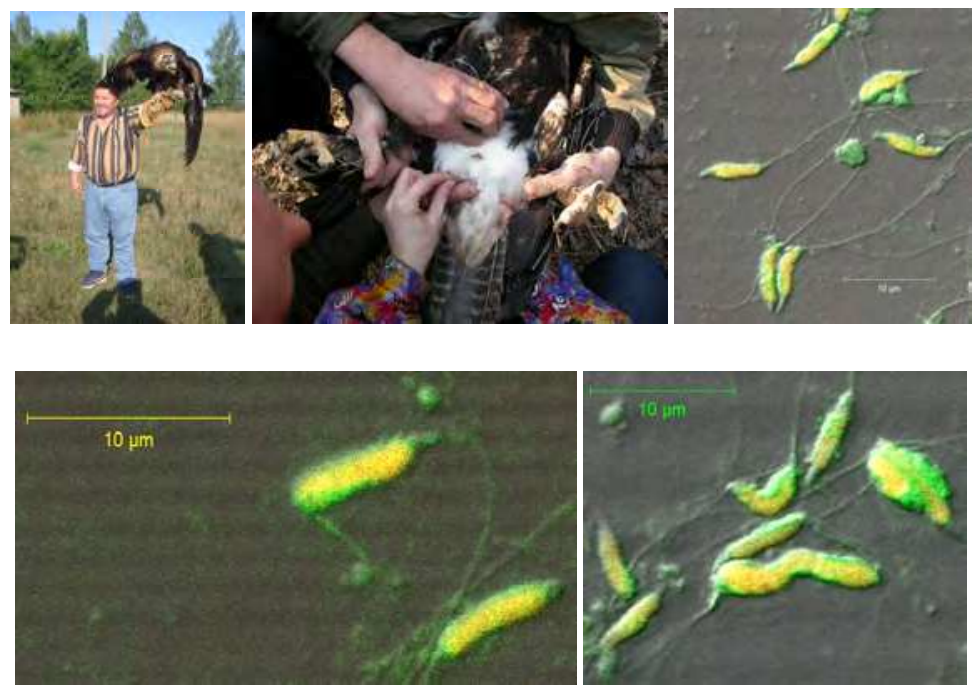

Fig. 8C. An attempt to vitrify sperm of the golden eagle, from left to right: I.I.K. with the bird; sperm retrieval process; fresh; slow frozen; and vitrified sperm. Slow frozen sperm protocol worked poorly, kinetic VF failed.

\section{Conclusion: "Race for the Pace": Is the universal cryo-protocol possible?}

The universal cryoprotocol, that would fit all types of cells, at least if they are in suspension on make a thin layer, would be the Holy Grail of cryobiology. Here is our hypothesis for consideration [Katkov, 2010]:

1. Every cell has its own critical rates of cooling and thawing, at which and higher the cell can be vitrified during cooling $\left(\boldsymbol{B}_{\text {cr_cool }}\right)$ and will not devitrify during warming $\left(\boldsymbol{B}_{\text {cr_warm }}\right)$ without any external "cryoprotectants" (they must be called "vitrificants" in this case). Or it might be just that non-lethal ice (i.e. cubical vs. hexagonal "killer ice") is formed during cooling and its transformation (recrystallization) to hexagonal type is precluded during warming. In any case, at rates higher than those two $\boldsymbol{B}_{c r}$ 's, the cell will survive without any exogenous compounds.

2. Those rates are substantially lower than predicted by the contemporary theories (Fahy and Rall, Boutron's work, Cravalho 's school: Toner, Karlsson, et al). We will not go into the details of the thermodynamics of the glassy state but the three main reasons are: i) presence of the internal cell vitrificants with high $T_{g}$; ii) small compartmentalized intracellular milieu; iii) no "true" extracellular VF is needed for survival as the cell has no time and shrink at such fast time. In any scenario, the cell survives if the pace of cooling and warming is higher than those two $\boldsymbol{B}_{c r}$ 's, and that is what matters.

3. The distribution and average values of those $\boldsymbol{B}_{c r}$ 's 's depend on the species of cells, particularly on the abundance of endogenous vitrificants, how "watery" those cells are, the level of compartmentalization, the size of the compartments, etc. It may well be that the same species (such embryos) might have very different $\boldsymbol{B}_{c r}$ 's at different stages of their development. 
4. We predict that while those speeds are relatively high for the majority of cell species (in range 200,00-1,000,000 OC/ $\mathrm{min}$ ), we have already achieved those critical rates in one well-documented case, namely humans as well as some other species of vertebrate sperm, thanks to the early work in the 1930s and by the Isachenkos in this century.

5. We believe that those high speeds are achievable for all species but that needs entirely new cryogenic equipment. Such rates if they are high enough to surpass the highest $\boldsymbol{B}_{c r}$ 's would be universally applicable to any type of suspendial and single cells so we will be witnessing the "Race for the Pace" very soon, some groups have been already actively working on it now.

Thermodynamic analysis of the most recent attempts of creating novel systems for kinetic VF such as cryogenic oscillating heat pipes [Jiao et al., 2006; Jiao et al., 2009], nano-droplets [Demirci \& Montsesano, 2007], quartz capillaries [Risco et al., 2007], and some others approaches that claim "ultra-fast" rates (see a comprehensive review by Criado in this Book), which in our opinion, do not produce the rates fast enough to reach the majority of $\mathrm{B}_{c r}$ 's without using exogenous permeable (and thus, potentially toxic) vitrificants. Thermodynamical considerations that prove this statement are not in the scope of this Chapter and will be done elsewhere. In fact, the hyper-fast rates of cooling and warming will be needed, and there is about of an order or two of magnitude difference between "ultra-" and "hyper-" (cf. ultrasonic and supersonic speed of flight as an example).

Introduction of such a "Universal Kinetic Vitrification Protocol" applicable for all cells (at least for those that are in suspension or make a thin attached layer) would shift the whole paradigm in cryopreservation of germplasm (and other types of suspendial cells) and in cryobiology as a science. It will require both new equipment for realization of hyper-fast rates (on which we are working now) and new methods of measurements. For example, it is not clear how $T_{h}, T_{m}$, and $T_{d}$ curves on the Fahy diagram would behave at speeds of cooling and warming in order of thousands ${ }^{\circ} \mathrm{C} / \mathrm{min}$, and how that could be measured: they may disappear completely! In any case, it will open not only the possibility of development of a uniform protocol and equipment for all existing and (which especially important) new types of cells and species, but it will also bring new, very challenging but exciting horizons for basic cryobiology as well.

\section{Epilogue: “In Defence of the Genius”(Editor's Reflection)}

\section{"In Defense of the Genius"}

Dr. Gregory Fahy called in his Chapter \#1A [Fahy \& Rall, 2007] the Luyet method and his promotion of kinetic VF as "Lyuet's tyranny" so my choice of words in this Chapter is just as a "symmetrical response "to that stye, nothing personal is intended. Greg spent a great deal of time in that and other numerous reviews and lectures describing the Luyet's unsuccessful attempts to implement K-VF in late 1930s -beginning of 1950's. However, we have not spent so much time in this Chapter on describing the failure to realize the promised potential of equilibrium VF and ice blockers for organ vitrification since 1984, even though Dr. Fahy and his colleagues have had in order of magnitude more resources, knowledge, and time than that of Father Luyet had had in 1939-1954. We would call this situation as being "stuck in the rut" and "the promise is not fulfilled".

At the same time, we completely agree with a statement that Fahy and Rall made in a subchapter titled "The ghost of Luyet": 
"Here we can only note the irony that, having been launched by breaking free of Luyet's tyranny of ultrarapid cooling, vitrification methods have now essentially turned back closer to Luyet's original idea of cooling as quickly as possible with minimal intracellular exposure to cryoprotectants [i.e., kinetic vitrifcation VF, I.I. K.],, albeit this time using at least marginally adequate concentrations of intracellular solutes. The ghost of Luyet lives on in the form of this ongoing methodological evolution, and we think he would have been pleased to see how his ideas about vitrification ultimately related to the now widespread use of vitrification as a practical and successful method of cryopreservation long after he, himself, had abandoned this approach."[Fahy \& Rall, 2007]

As a cryobiologist, who has been working in the same field, the Editor (at the Eves of 2012) might announce the following "resolutions":

- I wish cryonics would have been a real science;

- I wish ice-blockers would have been worked for the human body ;

- I wish cryonics would have preserve not only the "ghost" (we, actually, preserve SPIRIT of his science), but his body as well;

- $\quad$ I wish he could have been vitrified successfully in 1974 and re-warmed alive in 2012.

Had that all happened, Father Luyet would have been indeed thrilled to see how his method has been spread and are opening new horizons!

And for me, it is better to live under "tyranny" of the genius than under "ochlocracy" of the ignorant or "democracy" of the arrogant, and seeing as Wikipedia and other internet resources have been invaded (and infested) by cryonics "experts", and are full of their biographies, cryonic companies' descriptions, etc, while a reader can find neither biographies of Father Lyuet nor other prominent cryobiologists, both who passed away and live and in good health today. Unfortunately, Wikipedia has failed to be fair and balanced on this matter, but hope it'll change with time.

But that would be a topic of our other story, here we must stop and say just only that: kinetic vitrification of sperm, the early child of Father Luyett and the other pioneers of the cryobiological frontiers, is very much alive and on the march! And our own success and failures, honestly described in this Chapter, have only strengthened the position K-VF as a viable (not marginal!) and very promising method of cryopreservation.

\section{Appendix 1. Some peculiar similarities between [Fahy \& Rall, 2007] and our earlier papers, which are not cited there}

We invite the readers to compare the physical description of vitrification in that chapter by Fahy and Rall, particularly sub-chapter "The kinetic basis of vitrification", and the first part of the "Optimal storage below Tg" with our preceding publications (pp. 71 and 75 in [Katkov \& Levine, 2004] and pp. 353-4 "6. Storage at temperatures higher than $T_{g}$ of water" in [Katkov et al., 2006] respectively). The only substantial difference is that "the most widely used" WLF equation (25) in our paper [Katkov \& Levine, 2004].

$$
\eta(T)=\eta\left(T_{g}\right) 10^{\frac{-C_{1}\left(T-T_{g}\right)}{C_{2}+\left(T-T_{g}\right)}} \equiv \eta\left(T_{g}\right) e^{\frac{-2.303 C_{1}\left(T-T_{g}\right)}{C_{2}+\left(T-T_{g}\right)}}
$$

is replaced by the VTF equation in [Fahy \& Rall, 2007] as following:

$$
\eta(T)=\eta\left(T_{g}\right) e^{\frac{B}{T-T_{v}}}
$$


where $\eta(T)$ is the viscosity at temperature $T$ above the glass transition temperature $T_{\mathrm{g}}, \eta\left(T_{g}\right)$ is the viscosity at the glass transition tem temperature, $T_{v}$ is the "Vogel temperature" [Zhai \& Salomon, 2011] and $C_{1}, C_{2}$ and $B$ are empirical constants.

If the assumption of a linear relationship between the fractional free volume and temperature holds (free volume theory for WLF), VTF equation can be transformed into the WLF equation so the equations (1) and (2) must be combined as an equality, i.e.:

$$
\frac{-2.303 C_{1}\left(T-T_{g}\right)}{C_{2}+\left(T-T_{g}\right)} \equiv \frac{B}{T-T_{v}},
$$

which is true at any $T$ and $T_{g}$ in the range of being considered. Equalizing the numerators and denominators separately, the relationships between the WLF and VTF constants can be found as following:

$$
\begin{gathered}
C_{1} \equiv \frac{B}{2.303\left(T_{g}-T_{v}\right)} \\
C_{2} \equiv T_{g}-T_{v},
\end{gathered}
$$

which coincides with [Zhai \& Salomon, 2011].

Beside this substitution of WLF with VTF, which accordingly to [Zhai \& Salomon, 2011] "has a more profound physical meaning that relates both thermodynamic and kinetic concepts", there are definite similarities between [Fahy \& Rall, 2007] and [Katkov \& Levine, 2004; Katkov et al., 2006], which of course might be purely accidental (with a notion that those two papers had been sent to G.F. by I.I.K. well before 2007), so we will follow the spirit of the Open Access, namely "Let's the readers to decide".

\section{Appendix 2. On the recent paper by the Isachenkos on "vitrification in large volumes"}

Recently, the Isachenkos group published a report on vitrification of $500 \mu \mathrm{L}$ of human sperm vitrified with $0.25 \mathrm{M}$ sucrose Recently, the Isachenkos group published a report on vitrification of $500 \mu \mathrm{L}$ of human sperm vitrified with $0.25 \mathrm{M}$ sucrose [Isachenko et al., 2011]. Unfortunately, our two other teams that have co-authored this Chapter were not able to repeat the method: both human and bovine spermatozoa sperm survived vey poorly (single alive spermatozoa were observed) after vitrification in $0.5 \mathrm{~mL}$ straws. Interestingly enough, morphology of the sperm was practically intact (Fig. 9). This, together with the failure of the method even for $25 \mu \mathrm{L}$ droplets (another Isachenkos modification) to vitrify spermatozoa of polar bear and 4 raptor bird species described in the major text of this Chapter, indicates that the Isachenko method of "cryoprotectant"-free cryopreservation" works satisfactory for some species of sperm [Merino et al., 2011a; Merino et al., 2011b; Sanchez et al., 2011] but not for the others, and it is completely inapplicable to big and watery "oocytes and embryos. And without further clarification, the method of kinetic VF in "large volumes" have not been able to be repeated independently even for human and bovine sperm. Some of the questions that have been raised from other co-authors of the present Chapter in regards to that paper are: 


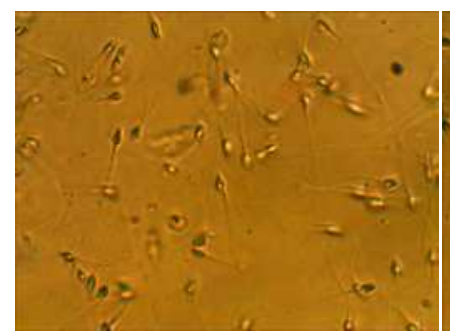

A (human native)

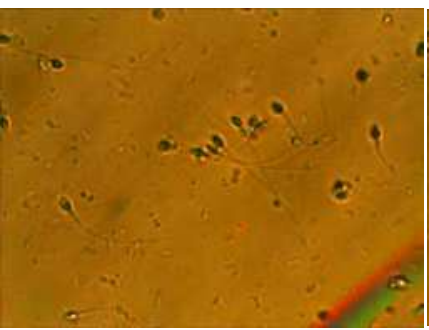

B (human, slow freezing)

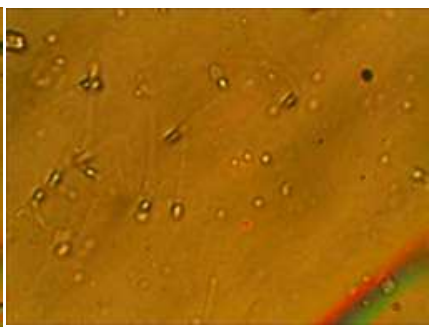

C (human, VF $0.5 \mathrm{~mL})$

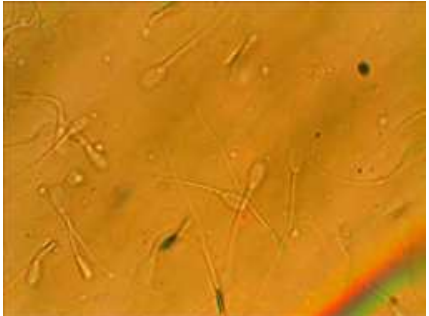

$\mathrm{D}$ (bull native)

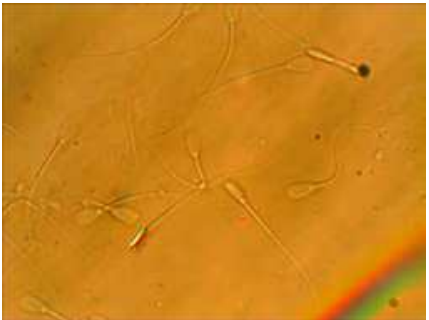

E (bull, slow freezing)

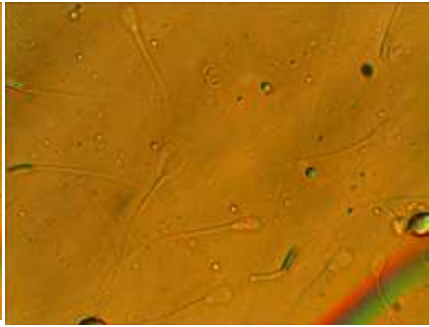

F (bull, VF $0.5 \mathrm{~mL}$ )

Fig. 9. Attempts to vitrify human (A-C) and bovine (D-F) spermatozoa using "large volume" $(500 \mu \mathrm{L})$ method [Isachenko et al., 2011]

$\mathbf{A}$ and $\mathbf{D}$ - native sperm, $\mathbf{B}$ and $\mathbf{E}$ spermatozoa frozen slowly with glycerol, $\mathbf{C}$ and $\mathbf{F}$ - sperm vitrified accordingly the Isachenko protocol.

Approximately $50 \%$ of human and bull sperm survived slow freezing, The vitrified cells are not visibly damaged but no motile spermatozoa were observed for both species

- Sucrose is considered as "natural" CPA while glycerol is not. See examples given in [Fahy \& Rall, 2007] about Alaskan beetles than can cumulate 10 Mole/L of glycerol!

- Glycerol cannot "dilute" intracellular osmolites - it can only add additional osmotic pressure inside the cell, thus, preventing more extensive shrinkage during slow freezing; that is exactly how it works as the CPA (not to be confused with its role in VF). Apparently, the authors confused it with the glycerol action as a plasticizer of the intracellular milieu, thus, lowering its $T_{g}$ inside the cells, but this is a completely different topic.

- Sucrose per se, as an impermeable solute, cannot directly penetrate internal organelles such as mitochondria; the role of sucrose, apparently, is to dehydrate the cells and make intracellular vitrification easier using lower cooling and warming rates. That in theory would allow us to vitrify larger volumes.

- It is not clear whether "It is known that human spermatozoa contain large amounts of proteins, sugars, and other components that make the intracellular matrix highly viscous and compartmentalized and may act as natural cryoprotectants" for the authors (the idea had been originated form the paper published in 2003 [Isachenko et al., 2003] but that that source is NOT referred) or it is a "common knowledge" (as the explanation of the 
possibility of kinetic VF of sperm) that had been recognized for many year prior to that publication in 2003. Note that the authors confused vitrificants with CPAs: intracellular proteins do not help slow freezing.

- Pre-cooling of the vitrified group is not detailed and it is not clear whether that grouped was pre-cooled at all.

Thus, there is a disparity in experimental verification of the method between several groups that have been contributed to this Chapter, which we feel should be clarified.

\section{References}

Angell C. A. (2004). "Amorphous water." Annu Rev Phys Chem 55: 559-83.

Beier A. F., Schulz J. C., Dörr D., Katsen-Globa A., Sachinidis A., Hescheler J. \&Zimmermann H. (2011). "Effective surface-based cryopreservation of human embryonic stem cells by vitrification." Cryobiology 63: 175-85.

Bernstein A. D. \&Petropavlovski V. V. (1937). "[Influence of non-electrolytes on viability of spermatozoa]." Buleten' Eksperimentalnoi Biologii i Medicini (Rus.) III(4225): 21-25.

Blanco J. M., George Gee G., Wildt D. E. \&Donoghue A. M. (2000). "Species Variation in Osmotic, Cryoprotectant, and Cooling Rate Tolerance in Poultry, Eagle, and Peregrine Falcon Spermatozoa." Biol Reprod 63,: 1164-1171.

Butler S. \&Pegg D. (2012). Precision in cryopreservation - equipment and control. In: Cryopreservation / Book 1 (ISBN 979-953-307-300-1). Eds:I. I. Katkov, InTech. 1: in press.

Chakraborty N., Chang A., Elmoazzen H., Menze M. A., Hand S. C. \&Toner M. (2011). "A Spin-Drying Technique for Lyopreservation of Mammalian Cells." Ann Biomed Eng 39: 1582-1591.

Cipri K., Lopez E. \&Naso V. (2010). "Investigation of the use of Pulse Tube in cell cryopreservation systems." Cryobiology 61: 225-30.

Demirci U. \&Montsesano G. (2007). "Cell encapsulating droplet vitrification." Lab Chip 7: 1428-1433.

Devireddy R. \&Thirumala S. (2011). "Preservation protocols for human adipose tissuederived adult stem cells." Methods Mol Biol 702: 369-394.

Erokhin A. S., Shishova N. V. \&Maksudov G. Y. (2007). "[A comparison of two diluents for the cryopreservation of ejaculated spermatozoa in spectacled bear (Tremarctos ornatus)]." [Reproduction in Domestic Animals] Rus. 42: 95-96.

Fahy G. M., MacFarlane D. R., Angell C. A. \&Meryman H. T. (1984). "Vitrification as an approach to cryopreservation." Cryobiology 21(4): 407-26.

Fahy G. M. \&Rall W. F. (2007). Vitrification: an overview. In: Vitrification in Assisted Reproduction: A User's Manual and Troubleshooting Guide. Eds:M. J. Tucker and J. Liebermann. London, UK, Infroma Healthcare. Ch.1A: 1-20.

Fahy G. M., Wowk B., R. P., Chang A., Phan J., Thomson B. \&Phan L. (2009). "Physical and biological aspects of renal vitrification." Organogenesis 5(165-175).

Foote R. H. (2002). "The history of artificial insemination: Selected notes and notables." J Anim Sci 80(E-Suppl. 2): E1-E10.

Gilmore J. A., Liu J., Gao D. Y. \&Critser J. K. (1997). "Determination of optimal cryoprotectants and procedures for their addition and removal from human spermatozoa." Hum Reprod 12(1): 112-8. 
Gordts S., Roziers P., Campo R. \&Noto V. (1990). "Survival and pregnancy outcome after ultrarapid freezing of human embryos." Fertil Steril 53(3): 469-72.

Graevsky E. Y. (1948a). "[Living matter and low temperatures]." Priroda (Rus.) 5: 13-25.

Graevsky E. Y. (1948b). "[Glassy state of protoplasm in conditions of deep cooling]." Uspehi Sovr. Biol. (Rus.) 14: 186-202.

Graevsky E. Y. \&Medvedeva Y. A. (1948). "[Causes of damage of protoplasm during deep freezing]." Zh. Obschey Biologii (Rus.) 9: 436-469.

Hoagland H. \&Pincus G. G. (1942). "Revival of mammalian sperm after immersion in liquid nitrogen." J Genet Physiol 25: 337-344.

Isachenko E., Isachenko V., Katkov I. I., Dessole S. \&Nawroth F. (2003). "Vitrification of mammalian spermatozoa in the absence of cryoprotectants: from past practical difficulties to present success." Reprod Biomed Online 6(2): 191-200.

Isachenko E., Isachenko V., Katkov I. I., Rahimi G., Schondorf T., Mallmann P., Dessole S. \&Nawroth F. (2004a). "DNA integrity and motility of human spermatozoa after standard slow freezing versus cryoprotectant-free vitrification." Hum Reprod 19(4): 932-9.

Isachenko E., Isachenko V. \&Katkov I. I. (2007). Cryoprotectant-Free Vitrification of Spermatozoa. In: Vitrification in Assisted Reproduction: A User's Manual and Troubleshooting Guide. Eds:M. J. Tucker and J. Liebermann. Oxon, UK, Infroma Healthcare Medical Books: 87-105.

Isachenko E., Isachenko V., Weiss J. M., Kreienberg R., Katkov I. I., Schulz M., Lulat A. G., Risopatron M. J. \&Sanchez R. (2008). "Acrosomal status and mitochondrial activity of human spermatozoa vitrified with sucrose." Reproduction 136(2): 167-73.

Isachenko E., Isachenko V., Sanchez R., Katkov I. I. \&Kreienberg R. (2010). Cryopreservation of spermatozoa: Old routine and new perspectives. In: Principles and Practice of Fertility Preservation. Eds:J. Donnez and S. S. Kim. Cambridge, UK,, Cambridge University Press: Ch. 14, pp 177-99.

Isachenko E., Mallmann P., Isachenko V., Rahimi G., Risopatron J. \&Sanchez R. (2012). Vitrification Technique- New Possibilities for Male Gamete Low-Temeprature Storage. In: Cryopreservation / Book 1 (ISBN 979-953-307-300-1). Eds:I. I. Katkov, inTech. 1: Chapter 2 (in press).

Isachenko V., Isachenko E., Katkov I. I., Montag M., Dessole S., Nawroth F. \&Van Der Ven H. (2004b). "Cryoprotectant-free cryopreservation of human spermatozoa by vitrification and freezing in vapor: effect on motility, DNA integrity, and fertilization ability." Biol Reprod 71(4): 1167-73.

Isachenko V., Isachenko E., Montag M., Zaeva V., Krivokharchenko I., Nawroth F., Dessole S., Katkov I. I. \&van der Ven H. (2005). "Clean technique for cryoprotectant-free vitrification of human spermatozoa." Reprod Biomed Online 10(3): 350-4.

Isachenko V., Maettner R., Petrunkina A. M., Mallmann P., Rahimi G., Sterzik K., Sanchez R., Risopatron J., Damjanoski I. \&Isachenko E. (2011). "Cryoprotectant-free vitrification of human spermatozoa in large (up to $0.5 \mathrm{~mL}$ ) volume: a novel technology." Clin Lab(57): 643-650.

Jahnel F. (1938). "[Resistance of human spermatozoa to deep cold]." Klinische Wochenschrift 17: $1273-1274$. 
Jiao A., Han X., Critser J. K. \&Ma H. (2006). "Numerical investigations of transient heat transfer characteristics and vitrification tendencies in ultra-fast cell cooling processes." Cryobiology 52(3): 386-92.

Jiao A. J., Ma H. B. \&Critser J. K. (2009). "Experimental investigation of cryogenic oscillating heat pipes." Int J Heat Mass Transf 52(15-16): 3504-3509.

Katkov I. I., Katkova N., Critser J. K. \&Mazur P. (1998). "Mouse spermatozoa in high concentrations of glycerol: chemical toxicity vs osmotic shock at normal and reduced oxygen concentrations." Cryobiology 37(4): 325-38.

Katkov I. I., Isachenko E., Isachenko V. \&Nawroth F. (2003). "Why can we vitrify mammalian spermatozoa without cryoprotectants? Physicochemical considerations." Cryobiology 47: 267.

Katkov I. I. \&Levine F. (2004). "Prediction of the glass transition temperature of water solutions: comparison of different models." Cryobiology 49(1): 62-82.

Katkov I. I., Isachenko V., Isachenko E., Kim M. S., Lulat A. G.-M. I., Mackay A. M. \&Levine F. (2006). "Low- and high- temperature vitrification as a new approach to biostabilization of reproductive and progenitor cells." Int J Refrigeration 29(3): 346-57.

Katkov I. I., Isachenko V. \&Isachenko E. (2007). Vitrification in Small Quenched Volumes with a Little Amount of or without Vitrificants: Biophysics and Thermodynamics. In: Vitrification in Assisted Reproduction: A User's Manual and Troubleshooting Guide. Eds:M. J. Tucker and J. Liebermann. London, UK, Infroma Healthcare: 21-32.

Katkov I. I. (2008). High temperature stabilization by drying and storage at ambient temperatures as the emerging alternative to transgenic animal sperm cryobanking. Int-1 Kirpichnkov's Conf. "Genetics, Selection, and Breeding of Fish", Saint-Petersburg, Russia.

Katkov I. I. (2010). "Race for the pace: is the universal cryoprotocol a dream or reality?" Cryobiology 61: 374-375.

Katkov I. I., Kan N. G., Cimadamore F., Nelson B., Snyder E. Y. \&Terskikh A. V. (2011). "DMSO-free programmed cryopreservation of fully dissociated and adherent human induced pluripotent stem cells. 2011:981606.." Stem Cells International 2011: 981606.

Koshimoto C., Gamliel E. \&Mazur P. (2000). "Effect of osmolality and oxygen tension on the survival of mouse sperm frozen to various temperatures in various concentrations of glycerol and raffinose." Cryobiology 41(3): 204-31.

Li X., Krawetz R., Liu S., Meng G. \&Rancourt D. E. (2008). "ROCK inhibitor improves survival of cryopreserved serum/feeder-free single human embryonic stem cells." Hum Reprod.

Lovelock J. E. (1953). "The mechanism of the protective action of glycerol against haemolysis by freezing and thawing." Biochim Biophys Acta 11(1): 28-36.

Luyet B. \&Hodapp A. (1938). "Revival of frog's spermatozoa vitrified in liquid air." Proc Meet Soc Exp Biol 39: 433-434.

Luyet B. E. (1937). "The vitrification of organic colloids and of protoplasm." Biodynamica 1: $1-14$. 
Maksudov G. Y., Shishova N. V. \&Katkov I. I. (2009). Ch. 8, In the Cycle of Life: Cryopreservation of Post-Mortem Sperm as a Valuable Source in Restoration of Rare and Endangered Species. In: Endangered Species: New Research. Eds:A. M. Columbus and L. Kuznetsov. Hauppauge, NY, NOVA Science Publishers: 189-240.

Martin-Ibanez R., Stromberg A. M., Hovatta O. \&Canals J. M. (2009). "Cryopreservation of dissociated human embryonic stem cells in the presence of ROCK inhibitor." Curr Protoc Stem Cell Biol Chapter 1: Unit 1C 8.

Martin-Ibanez R. (2012). Cryopreservation of human pluripotent stem cells: are we going in the right direction? In: Cryopreservation / Book 1 (ISBN 979-953-307-300-1). Eds:I. I. Katkov, InTech. 1: in press.

Mazur P. (1963). "Kinetics of Water Loss from Cells at Subzero Temperatures and the Likelihood of Intracellular Freezing." J Gen Physiol 47: 347-69.

Mazur P. (1970). "Cryobiology: the freezing of biological systems." Science 168(934): 939-49.

Mazur P., Leibo S. P. \&Chu E. H. Y. (1972). "2-factor hypothesis of freezing injury - evidence from chinese-hamster tissue-culture cell." Experimental Cell Res. 71: 345-349.

Mazur P. (1984). "Freezing of living cells: mechanisms and implications." Am J Physiol 247(3 Pt 1): C125-42.

Mazur P., Katkov I. I., Katkova N. \&Critser J. K. (2000). "The enhancement of the ability of mouse sperm to survive freezing and thawing by the use of high concentrations of glycerol and the presence of an Escherichia coli membrane preparation (Oxyrase) to lower the oxygen concentration." Cryobiology 40(3): 187-209.

Mazur P. \&Koshimoto C. (2002). "Is intracellular ice formation the cause of death of mouse sperm frozen at high cooling rates?" Biol Reprod 66(5): 1485-90.

Mazur P., Leibo S. P. \&Siedel G. E. (2008). "Cryopreservation of the germplasm of animals used in biological and medical research: Importance, impact, status, and future directions." Biol Reprod 78: 2-12.

Mazur P. \&Seki S. (2011). "Survival of mouse oocytes after being cooled in a vitrification solution to $-196^{\circ} \mathrm{C}$ at $95^{\circ}$ to $70,000^{\circ} \mathrm{C} / \mathrm{min}$ and warmed at $610^{\circ}$ to $118,000^{\circ} \mathrm{C} / \mathrm{min}$ : A new paradigm for cryopreservation by vitrification." Cryobiology 62: 1-7.

Merino O., Risopatron J., Sanchez R., Isachenko E., Figueroa E., Valdebenito I. \&Isachenko V. (2011a). "Fish (Oncorhynchus mykiss) spermatozoa cryoprotectant-free vitrification: stability of mitochondrion as criterion of effectiveness." Anim Reprod Sci 124(1-2): 125-31.

Merino O., Sanchez R., Risopatron J., Isachenko E., Katkov I. I., Figueroa E., Valdebenito I., Mallmann P. \&Isachenko V. (2011b). "Cryoprotectant-free vitrification of fish (Oncorhynchus mykiss) spermatozoa: first report." Andrologia: in press.

Milovanov V. K. (1962). [Reproductive Biology and Artificial Insemination of Animals] Rus. Moscow, Nauka.

Mollamohammadi S., Taei A., Pakzad M., Totonchi M., Seifinejad A., Masoudi N. \&Baharvand H. (2009). "A simple and efficient cryopreservation method for feederfree dissociated human induced pluripotent stem cells and human embryonic stem cells." Hum Reprod. 
Morris G. J. (2006). "Rapidly cooled human sperm: no evidence of intracellular ice formation." Human Reprod. 21(8): 2075-83.

Moskovtsev S. I., Lulat A. G. \&Librach C. L. (2012). Cryopreservation of Human Spermatozoa by Vitrification vs. Slow Freezing: Canadian Experience. In: Cryopreservation / Book 1 (ISBN 979-953-307-300-1). Eds:I. I. Katkov, inTech. 1: Chapter 3 (in press).

Nawroth F., Isachenko V., Dessole S., Rahimi G., Farina M., Vargiu N., Mallmann P., Dattena M., Capobianco G., Peters D., Orth I. \&Isachenko E. (2002). "Vitrification of human spermatozoa without cryoprotectants." CryoLetters 23(2): 93-102.

Okuyama M., Isogai S., Saga M., Hamada H. \&Ogawa S. (1990). "In vitro fertilization (IVF) and artificial insemination (AI) by cryopreserved spermatozoa in mouse." J Fertil Implant (Tokyo) 7: 116-119.

Park S. P., Lee Y. J., Lee K. S., Ah Shin H., Cho H. Y., Chung K. S., Kim E. Y. \&Lim J. H. (2004). "Establishment of human embryonic stem cell lines from frozen-thawed blastocysts using STO cell feeder layers." Hum Reprod 19(3): 676-84.

Parkes A. S. (1945). "Preservation of human spermatozoa at low temperatures." Br Med J 2: 212-213.

Perloff W. H., Steinberger E. \&Sherman J. K. (1964). "Conception with Human Spermatozoa Frozen by Nitrogen Vapor Technic." Fertil Steril 15: 501-4.

Polge C., Smith A. U. \&Parkes A. S. (1949). "Revival of spermatozoa after vitrification and dehydration at low temperatures." Nature 164: 666-676.

Pouplin M., Redl A. \&Gontard N. (1999). "Glass transition of wheat gluten plasticized with water, glycerol, or sorbitol." J Agric Food Chem 47(2): 538-43.

Rall W. F. \&Fahy G. M. (1985). "Ice-free cryopreservation of mouse embryos at -196 degrees C by vitrification." Nature 313(6003): 573-5.

Reubinoff B. E., Pera M. F., Vajta G. \&Trounson A. O. (2001). "Effective cryopreservation of human embryonic stem cells by the open pulled straw vitrification method." Hum Reprod 16(10): 2187-94.

Rezazadeh V. M., Eftekhari-Yazdi P., Karimian L., Hassani F. \&Movaghar B. (2009). "Vitrification versus slow freezing gives excellent survival, post warming embryo morphology and pregnancy outcomes for human cleaved embryos." J Assist Reprod Genet 26: 347-354.

Risco R., Elmoazzen H., Doughty M., He X. \&Toner M. (2007). "Thermal performance of quartz capillaries for vitrification." Cryobiology 55: 222-229.

Sanchez R., Risopatron J., Schulz M., Villegas J., Isachenko V., Kreinberg R. \&Isachenko E. (2011). "Canine sperm vitrification with sucrose: effect on sperm function." Andrologia.

Saragusty J. \&Arav A. (2011). "Current progress in oocyte and embryo cryopreservation by slow freezing and vitrification." Reproduction 141: 1-19.

Saragusty J. (2012). Genome Banking for Vertebrates Wildlife Conservation. In: Cryopreservation / Book 1 (ISBN 979-953-307-300-1). Eds:I. I. Katkov, InTech. 1: in press.

Schaffner C. S. (1942). "Longevity of fowl spermatozoa in frozen condition." Science 96: 337. 
Sherman J. K. (1963). "Questionable protection by intracellular glycerol during freezing and thawing." J Cell Comp Physiol 61: 67-83.

Sherman J. K. (1964). "Dimethyl Sulfoxide as a Protective Agent During Freezing and Thawing of Human Spermatozoa." Proc Soc Exp Biol Med 117: 261-4.

Smirnov I. V. (1949). "Preservation of domestic animal semen by deep cooling." Sovetskaja Zootechnia (Rus.). 4: 63-65.

Spallanzani L. (1780). "Dissertazioni di fisica animale e vegetale." Modano.

Stiles W. (1930). "On the cause of cold death of plants." Protoplasma 9: 459-468.

Stubban C., Wesselschmidt R. L., Loring J. F. \&Katkov I. I. (2007). Cryopreservation of human embryonic stem cells. In: Human Stem Cell Manual. A Laboratory Guide. Eds:J. F. Loring, R. L. Wesselschmidt and P. H. Schwartz. London, Elsevier: 47-55.

Suzuki H. (2006). "Freeze-dried Spermatozoa and Freeze-dried Sperm Injection into Oocytes." J Mamm Ova Res(23): 91-95.

Tada N., Sato M., Yamanoi J., Mizorogi T., Kasai K. \&Ogawa S. (1990). "Cryopreservation of mouse spermatozoa in the presence of raffinose and glycerol." J Reprod. Fertil 89: 511-516.

Tucker M. J. \&Liebermann J., Eds. (2007). Vitrification in Assisted Reproduction: A User's Manual and Troubleshooting Guide. London, UK, Infroma Healthcare.

Wagh V., Meganathan K., Jagtap S., Gaspar J. A., Winkler J., Spitkovsky D., Hescheler J. \& Sachinidis A. (2011). "Effects of cryopreservation on the transcriptome of human embryonic stem cells after thawing and culturing." Stem Cell Rev 7: 506-517.

Ware C. B. \&Baran S. W. (2007). "A controlled-cooling protocol for cryopreservation of human and non-human primate embryonic stem cells." Methods Mol Biol 407: 43-9.

Whittingham D. G., Leibo S. P. \&Mazur P. (1972). "Survival of mouse embryos frozen to -196 degrees and -269 degrees C." Science 178(59): 411-4.

Wikipedia (2011a). "21st Century Medicine." http://en.wikipedia.org/wiki/Twenty-First_Century_Medicine.

Wikipedia (2011b). "KrioRus." http:/ /en.wikipedia.org/wiki/KrioRus.

Wikipedia (2011c). "Danila Medvedev." http://en.wikipedia.org/wiki/Danila_Medvedev.

Wilmut I. (1972). "The effect of cooling rate, warming rate, cryoprotective agent and stage of development on survival of mouse embryos during freezing and thawing." Life Sci II 22: 1071-1079.

Yokoyama M., Akiba H., Katsuki M. \&Nomura T. (1990). "Production of normal young following transfer of mouse embryos obtained by in vitro fertilization using cryopreserved spermatozoa." Exp. Anim 39: 125-138.

Zhai H. \& Salomon D. (2011). "Low Temperature Property Evaluation and Fragility of Asphalt Binders Using Non-Arrhenius Viscosity Temperature Dependency." http://www.technopave.com/publications/Fragility-of-Asphalt-Non-ArrheniusViscosity.pdf 05-0971. 
Zhou C. Q., Mai Q. Y., Li T. \&Zhuang G. L. (2004). "Cryopreservation of human embryonic stem cells by vitrification." Chin Med J (Engl) 117(7): 1050-5. 


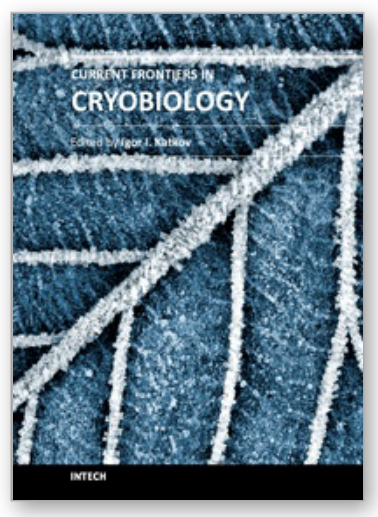

\section{Current Frontiers in Cryobiology}

Edited by Prof. Igor Katkov

ISBN 978-953-51-0191-8

Hard cover, 574 pages

Publisher InTech

Published online 09, March, 2012

Published in print edition March, 2012

Almost a decade has passed since the last textbook on the science of cryobiology, Life in the Frozen State, was published. Recently, there have been some serious tectonic shifts in cryobiology which were perhaps not seen on the surface but will have a profound effect on both the future of cryobiology and the development of new cryopreservation methods. We feel that it is time to revise the previous paradigms and dogmas, discuss the conceptually new cryobiological ideas, and introduce the recently emerged practical protocols for cryopreservation. The present books, "Current Frontiers in Cryobiology" and "Current Frontiers in Cryopreservation" will serve the purpose. This is a global effort by scientists from 27 countries from all continents and we hope it will be interesting to a wide audience.

\section{How to reference}

In order to correctly reference this scholarly work, feel free to copy and paste the following:

I.I. Katkov, V.F. Bolyukh, O.A. Chernetsov, P.I. Dudin, A.Y. Grigoriev, V. Isachenko, E. Isachenko, A.G.-M. Lulat, S.I. Moskovtsev, M.P. Petrushko, V.I. Pinyaev, K.M. Sokol, Y.I. Sokol, A.B. Sushko and I. Yakhnenko (2012). Kinetic Vitrification of Spermatozoa of Vertebrates: What Can We Learn from Nature?, Current Frontiers in Cryobiology, Prof. Igor Katkov (Ed.), ISBN: 978-953-51-0191-8, InTech, Available from: http://www.intechopen.com/books/current-frontiers-in-cryobiology/kinetic-vitrfiication-of-sperm-of-vertebrateswhat-can-we-learn-from-nature-

\section{INTECH}

open science | open minds

\section{InTech Europe}

University Campus STeP Ri

Slavka Krautzeka 83/A

51000 Rijeka, Croatia

Phone: +385 (51) 770447

Fax: +385 (51) 686166

www.intechopen.com

\section{InTech China}

Unit 405, Office Block, Hotel Equatorial Shanghai

No.65, Yan An Road (West), Shanghai, 200040, China

中国上海市延安西路65号上海国际贵都大饭店办公楼 405 单元

Phone: +86-21-62489820

Fax: $+86-21-62489821$ 
(C) 2012 The Author(s). Licensee IntechOpen. This is an open access article distributed under the terms of the Creative Commons Attribution 3.0 License, which permits unrestricted use, distribution, and reproduction in any medium, provided the original work is properly cited. 